\title{
ORNL/TM-2015/551
}

\section{Total Dissolved Gas Prediction and Optimization in RIVERWARE}

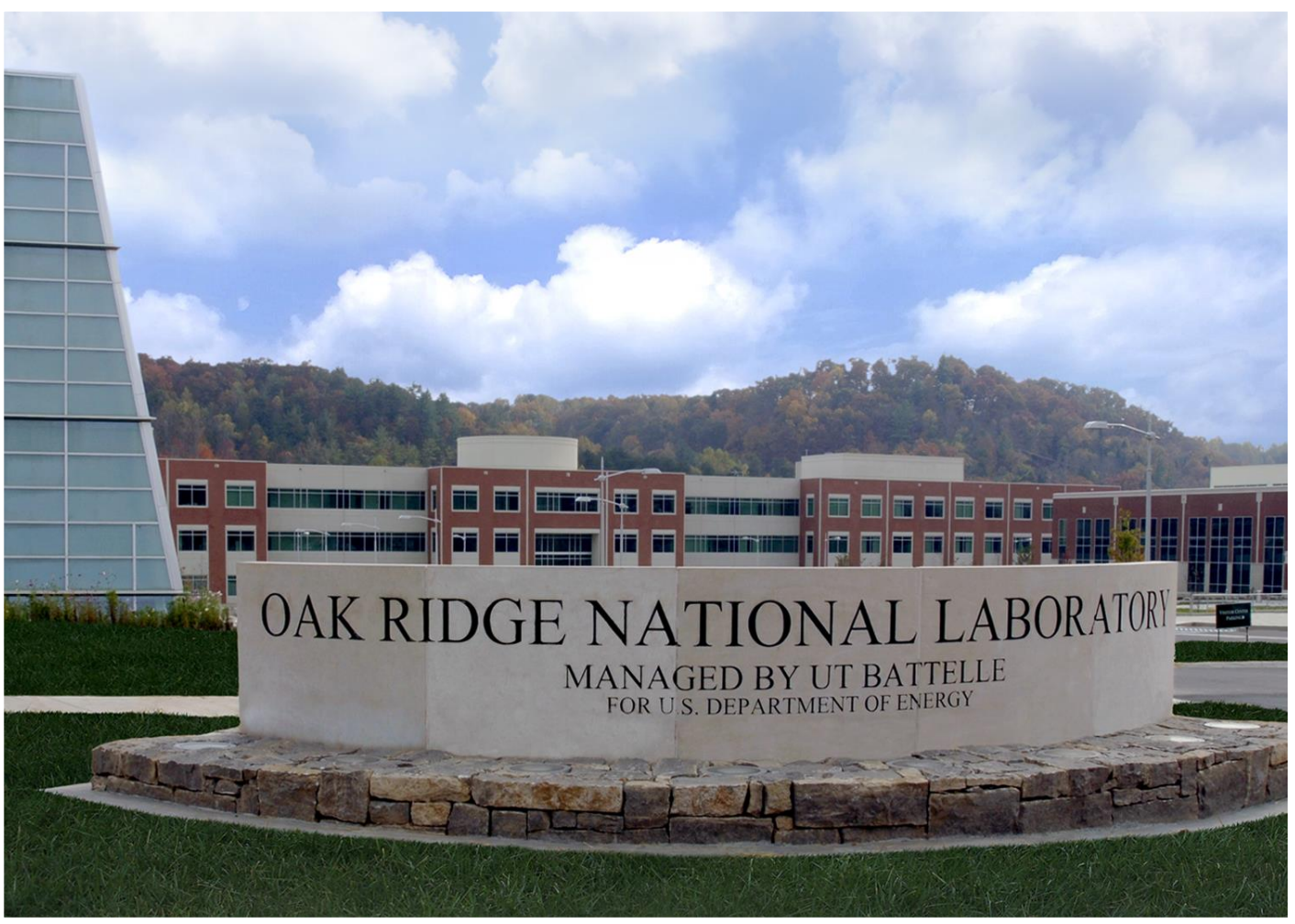

Approved for public release. Distribution is unlimited.
Kevin M. Stewart Adam Witt

Boualem Hadjerioua

September 2015 


\section{DOCUMENT AVAILABILITY}

Reports produced after January 1, 1996, are generally available free via US Department of Energy (DOE) SciTech Connect.

Website http://www.osti.gov/scitech/

Reports produced before January 1, 1996, may be purchased by members of the public from the following source:

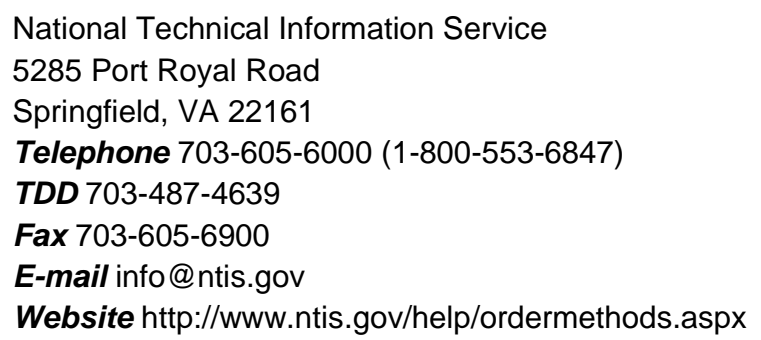

Reports are available to DOE employees, DOE contractors, Energy Technology Data Exchange representatives, and International Nuclear Information System representatives from the following source:

Office of Scientific and Technical Information

PO Box 62

Oak Ridge, TN 37831

Telephone 865-576-8401

Fax 865-576-5728

E-mail reports@osti.gov

Website http://www.osti.gov/contact.html

This report was prepared as an account of work sponsored by an agency of the United States Government. Neither the United States Government nor any agency thereof, nor any of their employees, makes any warranty, express or implied, or assumes any legal liability or responsibility for the accuracy, completeness, or usefulness of any information, apparatus, product, or process disclosed, or represents that its use would not infringe privately owned rights. Reference herein to any specific commercial product, process, or service by trade name, trademark, manufacturer, or otherwise, does not necessarily constitute or imply its endorsement, recommendation, or favoring by the United States Government or any agency thereof. The views and opinions of authors expressed herein do not necessarily state or reflect those of the United States Government or any agency thereof. 


\title{
Environmental Sciences Division
}

\section{TOTAL DISSOLVED GAS PREDICTION AND OPTIMIZATION IN RIVERWARE}

\author{
Kevin M. Stewart \\ Adam Witt \\ Boualem Hadjerioua
}

Date Published: September 2015

\author{
Prepared for \\ U.S. Department of Energy \\ Wind and Water Program \\ Prepared by \\ OAK RIDGE NATIONAL LABORATORY \\ Oak Ridge, Tennessee 37831-6283 \\ Managed by \\ UT-BATTELLE, LLC \\ for the \\ US DEPARTMENT OF ENERGY \\ under contract DE-AC05-00OR22725
}




\section{TABLE OF CONTENTS}

Page

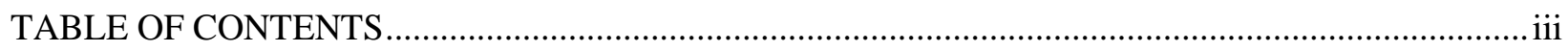

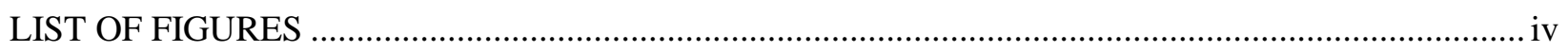

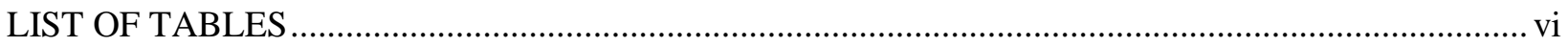

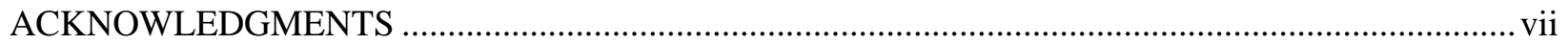

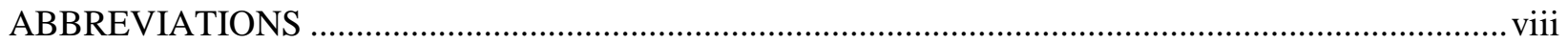

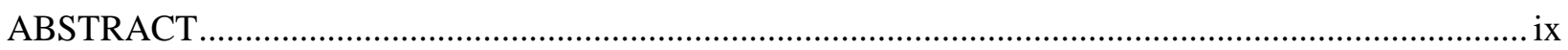

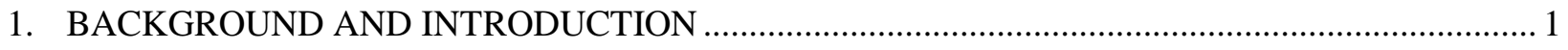

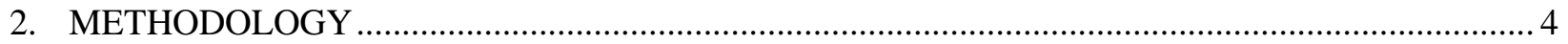

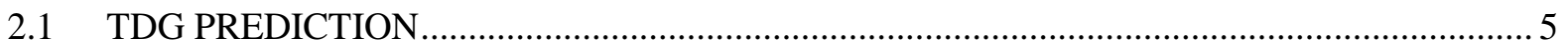

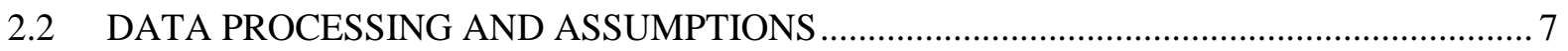

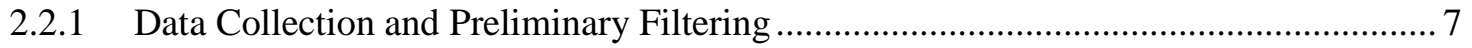

2.2.2 Project Specific Data Filtering and Assumptions .................................................. 9

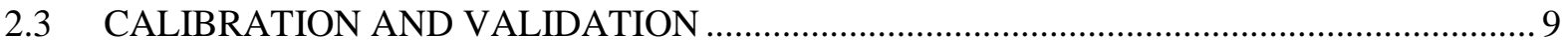

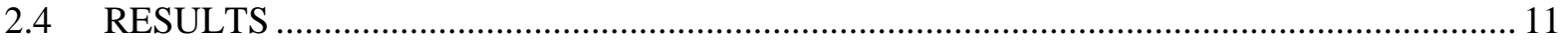

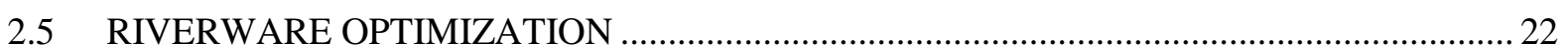

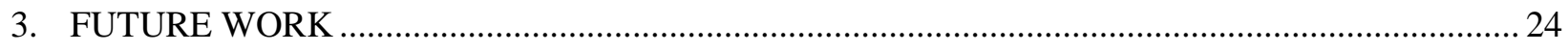

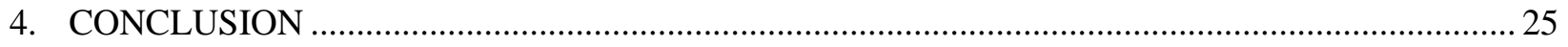

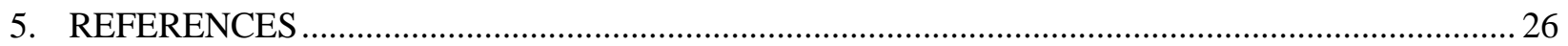




\section{LIST OF FIGURES}

Figure

Page

Figure 1 - Map depicting major dams along the Columbia and Snake Rivers. The Study area (mid-C) is highlighted in yellow Source: U.S. Army Corps of Engineers (2015 online)..... 3

Figure 2 - Advantages and disadvantages associated with direct (CFD) and indirect (empirical) modeling approaches for predicting TDG levels.

Figure 3 - Project development of TDG prediction based techniques employed in a reservoir system modeling tool.......

Figure 4-Physical processes of hydro and dam operation governing the development of the TDG predictive methodology.

Figure 5 - Scatter plot for measured verses simulated TDG levels at the tailrace of Grand Coulee Dam (data points are color coded by spill).

Figure 6-Scatter plot for measured verses simulated TDG levels at the tailrace of Chief Joseph Dam (data points are color coded by spill).

Figure 7 -Scatter plot for measured verses simulated TDG levels at the tailrace of Wells Dam (data points are color coded by spill).

Figure 8-Scatter plot for measured verses simulated TDG levels at the tailrace of Rocky Reach Dam (data points are color coded by spill).

Figure 9 - Scatter plot for measured verses simulated TDG levels at the tailrace of Rock Island Dam (data points are color coded by spill).

Figure 10 - Scatter plot for measured verses simulated TDG levels at the tailrace of Wanapum Dam (data points are color coded by spill).

Figure 11 - Scatter plot for measured verses simulated TDG levels at the tailrace of Priest

Rapids Dam (data points are color coded by spill).

Figure 12 - Time series plots for powerhouse and spillway flows and measured verses simulated TDG levels at the tailrace of Grand Coulee Dam for the calibrated and validated cases.

Figure 13 - Time series plots for powerhouse and spillway flows and measured verses simulated TDG levels at the tailrace of Chief Joseph Dam for the calibrated and validated cases.

Figure 14 - Time series plots for powerhouse and spillway flows and measured verses simulated TDG levels at the tailrace of Wells Dam for the calibrated and validated cases.

Figure 15 - Time series plots for powerhouse and spillway flows and measured verses simulated TDG levels at the tailrace of Rocky Reach Dam for the calibrated and validated cases 18 
Figure 16 - Time series plots for powerhouse and spillway flows and measured verses simulated TDG levels at the tailrace of Rock Island Dam for the calibrated and validated cases

Figure 17 - Time series plots for powerhouse and spillway flows and measured verses simulated TDG levels at the tailrace of Wanapum Dam for the calibrated and validated cases

Figure 18 - Time series plots for powerhouse and spillway flows and measured verses simulated TDG levels at the tailrace of Priest Rapids Dam for the calibrated and validated cases 21

Figure 19 - Process framework of optimization execution within RiverWare

Figure 20 - Schematic depicting reservoir TDG level predictive methodology .25 


\section{LIST OF TABLES}

Table

Page

Table 1 - Hourly data collected from USACE databases for seven Columbia River Basin projects............ 8

Table 2 - Constant coefficients representing TDG reuptake in reference to background reservoir

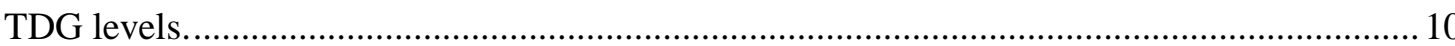

Table 3 - Constant coefficients representing TDG reuptake in reference to background reservoir

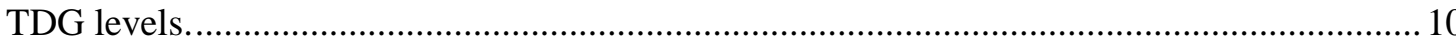

Table 4 - Coefficients and performance statistics for TDG predictions................................................ 11 


\section{ACKNOWLEDGMENTS}

The authors would like to acknowledge and express their appreciation to all the following individuals and programs for their review, comments, contributions, and support of this report:

\section{United States Department Of Energy (DOE)}

- Hoyt Battey

- Jocelyn Brown-Saracino

IIHR - Engineering and Hydroscience at University of Iowa

- Marcela Politano

- Alejandro Castro

- Larry Weber

\section{CADSWES}

- Edith Zagona

- Timothy McGee

- David Neumann

- Mitch Clement

\section{USBR}

- Merlynn Bender

Public Utility District No.1 Of Chelan County

- Scott Buehn

\section{ORNL}

- Scott DeNeale

- Abigail Maloof

- Ethan Hopping 


\section{ABBREVIATIONS}

$\begin{array}{ll}\text { ANN } & \text { Artificial Neural Network } \\ \text { CADSWES } & \text { University of Colorado's Center for Advanced Decision Support for Water and } \\ & \text { Environmental Systems } \\ \text { CFD } & \text { Computational Fluid Dynamics } \\ \text { CRB } & \text { Columbia River Basin } \\ \text { DOE } & \text { Department of Energy } \\ \text { ESA } & \text { Endangered Species Act } \\ \text { GBD } & \text { Gas Bubble Disease } \\ \text { GP } & \text { Genetic Programming } \\ \text { HWQR } & \text { Historical Water Quality Reports } \\ \text { ORNL } & \text { Oak Ridge National Laboratory } \\ \text { PUD } & \text { Public Utility District } \\ \text { RMSE } & \text { Root Mean Square Error } \\ \text { TDG } & \text { Total Dissolved Gas } \\ \text { USACE } & \text { United States Army Corps of Engineers } \\ \text { USBR } & \text { Bureau of Reclamation } \\ \text { USEPA } & \text { U.S. Environmental Protection Agency } \\ \text { WES } & \text { Waterways Experiment Station }\end{array}$




\begin{abstract}
Management and operation of dams within the Columbia River Basin (CRB) provides the region with irrigation, hydropower production, flood control, navigation, and fish passage. These various systemwide demands can require unique dam operations that may result in both voluntary and involuntary spill, thereby increasing tailrace levels of total dissolved gas (TDG) which can be fatal to fish. Appropriately managing TDG levels within the context of the systematic demands requires a predictive framework robust enough to capture the operationally related effects on TDG levels.
\end{abstract}

Development of the TDG predictive methodology herein attempts to capture the different modes of hydro operation, thereby making it a viable tool to be used in conjunction with a real-time scheduling model such as RiverWare. The end result of the effort will allow hydro operators to minimize system-wide TDG while meeting hydropower operational targets and constraints.

The physical parameters such as spill and hydropower flow proportions, accompanied by the characteristics of the dam such as plant head levels and tailrace depths, are used to develop the empirically-based prediction model. In the broader study, two different models are developed - a simplified and comprehensive model. The latter model incorporates more specific bubble physics parameters for the prediction of tailrace TDG levels. The former model is presented herein and utilizes an empirically based approach to predict downstream TDG levels based on local saturation depth, spillway and powerhouse flow proportions, and entrainment effects. Representative data collected from each of the hydro projects is used to calibrate and validate model performance and the accuracy of predicted TDG uptake. ORNL, in conjunction with IIHR - Hydroscience \& Engineering, The University of Iowa, carried out model adjustments to adequately capture TDG levels with respect to each plant while maintaining a generalized model configuration. Validation results indicate excellent model performance with coefficient of determination values exceeding $92 \%$ for all sites. This approach enables model extension to an increasingly wider array of hydropower plants, i.e., with the proper data input, TDG uptake can be calculated independent of actual physical component design.

The TDG model is used as a module in the systematic optimization framework of RiverWare, a river and reservoir modeling tool used by federal agencies, public utility districts, and other dam owners and operators to forecast, schedule, and manage hydropower assets. The integration and testing of the TDG module within RiverWare, led by University of Colorado's Center for Advanced Decision Support for Water and Environmental Systems (CADSWES), will allow users to generate optimum system schedules based on the minimization of TDG. Optimization analysis and added value will be quantified as systemwide reductions in TDG achieved while meeting existing hydropower constraints.

Future work includes the development of a method to predict downstream reservoir forebay TDG levels as a function of upstream reservoir tailrace TDG values based on river hydrodynamics, hydro operations, and reservoir characteristics. Once implemented, a holistic model that predicts both TDG uptake and transport will give hydropower operators valuable insight into how system-wide environmental effects can be mitigated while simultaneously balancing stakeholder interests. 


\section{BACKGROUND AND INTRODUCTION}

Total dissolved gas (TDG) supersaturation in waters released at hydropower dams can cause gas bubble trauma in fish, resulting in physical injury and eyeball protrusion that can lead to mortality. Elevated TDG concentrations at hydropower facilities are generally caused by the entrainment of air in spillway releases and the subsequent exchange of atmospheric gasses into solution during the transport of bubbles through the stilling basin. TDG refers to the total amount of dissolved gases present in water. Elevated TDG is recognized as a serious problem on the Columbia and Snake Rivers where, in the 1960's, it first became evident that TDG supersaturation caused gas bubble disease (GBD) in numerous fish species present in the Columbia River Basin (Ebel 1969). The effect of TDG supersaturation is complex and depends principally on TDG concentration, exposure time, fish life stage, and swimming depth of the fish (Stroud et al. 1975, Weitkamp and Katz 1980, Bouck 1980). An early review of the gas supersaturation problem in the Columbia River basin is found at USEPA (1971). Comprehensive reviews of studies found in the literature related to biological effects of TDG on fish are documented in Weitkamp (2008a, 2008b).

In the northwestern U.S., dam operations are constrained by state and federal water quality standards for TDG saturation, which help balance the benefits of spillway operations designed for Endangered Species Act (ESA)-listed fisheries with the need to maintain adequate water quality. In the 1970s, the United States Environmental Protection Agency (USEPA), under the federal Clean Water Act (Section 303(d)), established a criterion to protect freshwater and marine aquatic life, stating hydropower tailwaters cannot exceed the TDG supersaturation level of $110 \%$. The states of Washington and Oregon have adopted water quality standards for TDG saturation in the tailrace and forebays of hydropower facilities on the Columbia and Snake Rivers where spillway operations support fish passage objectives.

TDG production depends on a progression of complex processes. The large energy introduced by spillway flows, mostly dissipated in the stilling basin and adjoining tailwater channel, introduces massive amounts of bubbles and creates energetic waves and sprays. When bubbles are carried down to deep, high-pressure regions of the stilling basin, the increased solubility of air in water promotes air transfer from bubbles into water. In these deep regions, the bubble size distribution is in constant flux due to both dissolution and compression. The amount of air entrained on the spillway and during plunging of spillway flows, the breakup and coalescence of entrained bubbles, and the rate of mass transfer between bubbles and water are all variables that affect TDG production. As an additional complexity, the TDG distribution downstream of dams is strongly coupled with the hydrodynamics in the tailrace and river downstream. A lateral gradient of TDG is frequently observed in tailraces due to the location of the spillway or operation of the dam. Mixing with powerhouse flows can play an important role in the resulting TDG profile downstream of the dam. Degasification at the free surface can also be important in the routing of TDG in the reservoir from project to project.

Predicting TDG production and behavior is a challenge. There are several quantitative assessments/methodologies for predicting TDG based on physical (mechanistic) and empirical methodologies. The various physically based models rely on a wide array of input parameters ranging from small-scale bubble mass transfer quantities involving bubble diameters, gas void ratios, kinetic energies and viscosities, diffusion coefficients, and surface tension to larger-scale parameters like stilling 
basin depths, spillway widths, water depths, spillway and total flows, and hydraulic head. Some models are based on mass transfer of air bubbles into the water and through direct air-water surface gas transfer. Urban et al. (2008) presented a model to predict TDG saturation just downstream of a spillway based on physical processes of mass transfer. The effects of bubble size distribution (Politano et al., (2007, 2005, 2003) and bubble volume and normal velocity fluctuation attenuation (Turan et al., 2007) have been studied to better understand and model air entrainment. Physically-based models have incorporated geometrical aspects of the dams such as stilling basin and river depths (Geldert et al., 1998), spillway configurations and flow parameters (Hibbs and Gulliver, 1997), upstream TDG concentration (Roesner and Norton, 1971), and flood discharge characteristics, such as water depths and pressures (Ran et al., 2009), to predict gas transfer and downstream TDG levels. Columbia Basin Research (2000) uses two physically based equations in their U.S. Army Corps of Engineers (USACE) CRiSP Model 1.6, which are based on the physical processes of producing spill and dissolving excess TDG. This procedure is based on the model developed by Roesner and Norton (1971) and includes geometric information about the spill bay and gas entrainment physics. Computational fluid dynamics (CFD) models have been used to model TDG exchange, mixing, and transport (Xiao-li et al., 2010 and Weber et al., 2004). However, the computational effort necessary to resolve the smallest bubbles responsible for mass transfer is prohibitive (Witt et al., 2015), and CFD models, in addition to methodologies used in the physically based TDG prediction models, require calibration of many equation coefficients specific to each case.

Whereas physically based methodologies rely on the mass transfer occurring in two-phase flow regimes, as defined by conservation equations of momentum and mass, empirical approaches analyze the behaviors and correlative trends of the physical parameters using various data-mining and curve-fitting techniques. Columbia Basin Research (2000) uses four empirical equations in their CRiSP Model 1.6 developed by the USACE Waterways Experiment Station (WES) as a part of the Dissolved Gas Abatement Study (USACE, 1997). Artificial neural network (ANN) and genetic programming (GP) approaches have been used to predict TDG. The ANN resulted in lower root-mean-square (RMS) errors and resolved TDG levels associated with lower spill flow when compared with standard multivariate regression models. Expressions are derived for TDG levels based on parameters like spill, upstream temperature, and actual TDG levels, but they are specific for each case and not very portable or applicable to other dams. AbdulAziz et al. (2007a, 2007b) proposed an empirical model based on an extended stochastic harmonic analysis algorithm to predict dissolved oxygen, which is one of the main constituents of TDG. Fourier transform analysis was used to determine certain model coefficients. Though, a multitude of predictive models exist, supporting real-time predictions within the context of a hydro operations forecasting model is currently not available.

Hydro operations currently adjust spill priorities during real-time operation based on observation and operator experience - a certain project is requested to spill up to a given flow rate, then the next project up to a different flow rate, and so on. A science- and physics - based method or protocol to predict and minimize TDG levels within the context of hydro planning operations is strongly required to effectively and holistically manage systematic river operations. Due to the high uncertainty in predicting daily TDG uptake from spill effects, it is difficult to efficiently plan and control the system for short to long-term periods of time. The RiverWare hydro system modeling software is currently being used to model and help plan hydro operations along the mid-Columbia River Basin with respect to water management, availability, and storage capacity within the context of power generation. 
Understanding the complex processes affecting TDG levels while controlling spillway operations and hydro demands to meet water quality standards, coupled with the need to maintain high overall system efficiency, is a balancing act consistently proven difficult to manage, predict, and control. There is an apparent and present need for advanced tools, techniques, and software to assist in hydropower forecasting and optimization that minimizes environmental impacts while maximizing system-wide benefits.

Oak Ridge National Laboratory (ORNL), with funding from the U.S. Department of Energy (DOE) and in conjunction with Iowa Hydroscience \& Engineering Department at the University of Iowa and CADSWES with the University of Colorado, have developed a methodology for predicting total dissolved gas (TDG) uptake at the following Columbia River dams: Grand Coulee, Chief Joseph, Wells, Rocky Reach, Rock Island, Wanapum, and Priest Rapids (highlighted in Figure 1). This generalized TDG exchange model is calibrated for each specific project and is subsequently being used in conjunction with the reservoir system modeling software RiverWare to optimize system-wide hydroelectric generation while minimizing TDG production. This work extends from initial explorations and preliminary foundations established for predicting and managing TDG levels in the northwest (Pasha et al. 2012, Hadjerioua et al. 2014).

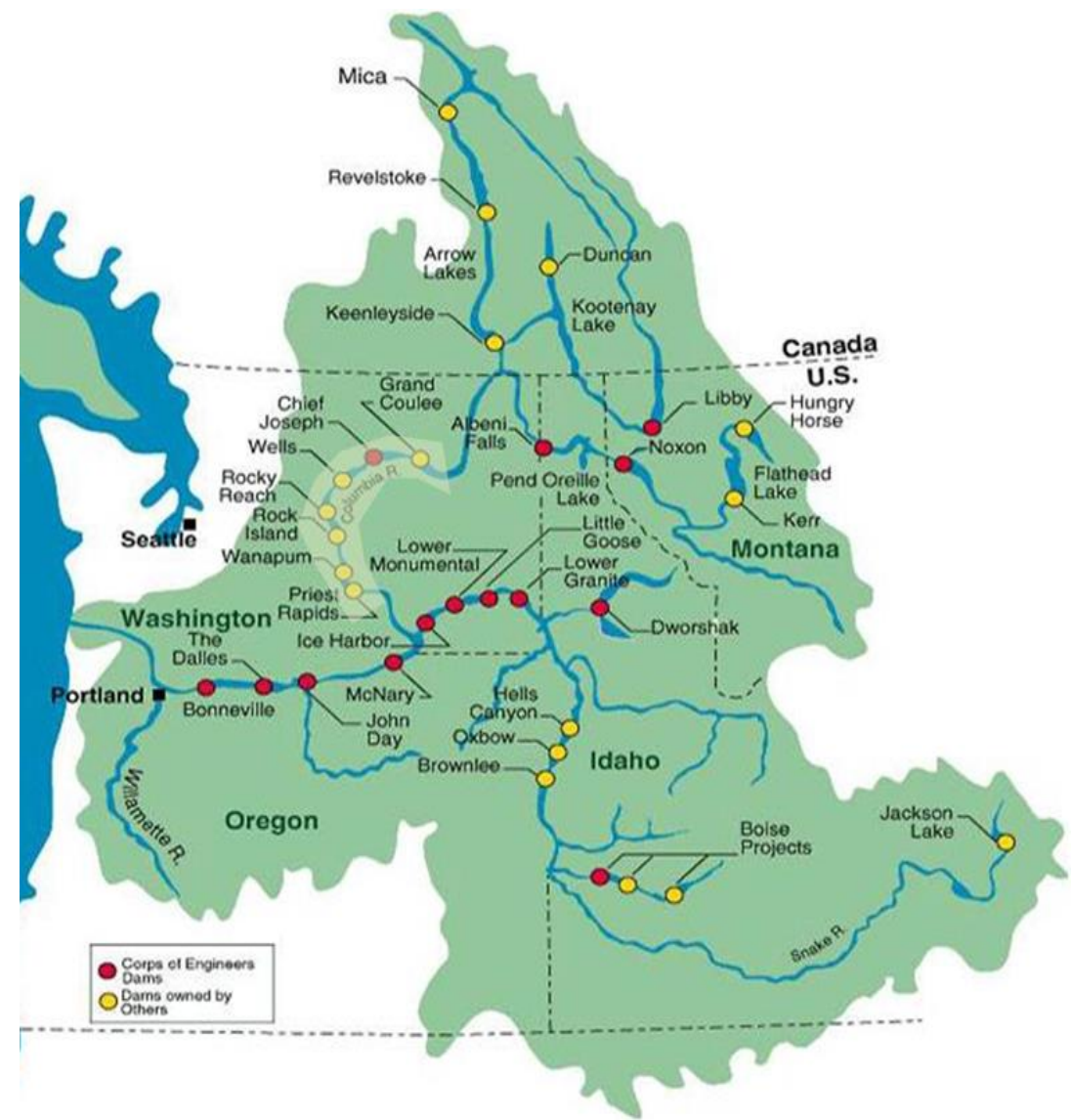

Figure 1 - Map depicting major dams along the Columbia and Snake Rivers. The Study area (mid-C) is highlighted in yellow Source: U.S. Army Corps of Engineers (2015 online). 


\section{METHODOLOGY}

The majority of the approaches for predicting TDG levels can be divided into two modeling methods: 1) direct modeling of large scale physical processes to predict TDG using high fidelity models such as computational fluid dynamics (CFD) and, 2) empirical modeling of physical processes to predict TDG using regression-type models. Whereas the former approach provides TDG estimates based on precise spatial and temporal assessments, it is difficult to implement in a real-time forecasting framework due to the cost and time overhead associated with running and applying site specific, computationally demanding simulations. In contrast, the regression modeling approach is ideal for use in a real-time forecasting structure since they provide quick, efficient, and reasonably accurate predictions of TDG levels (Figure 2).

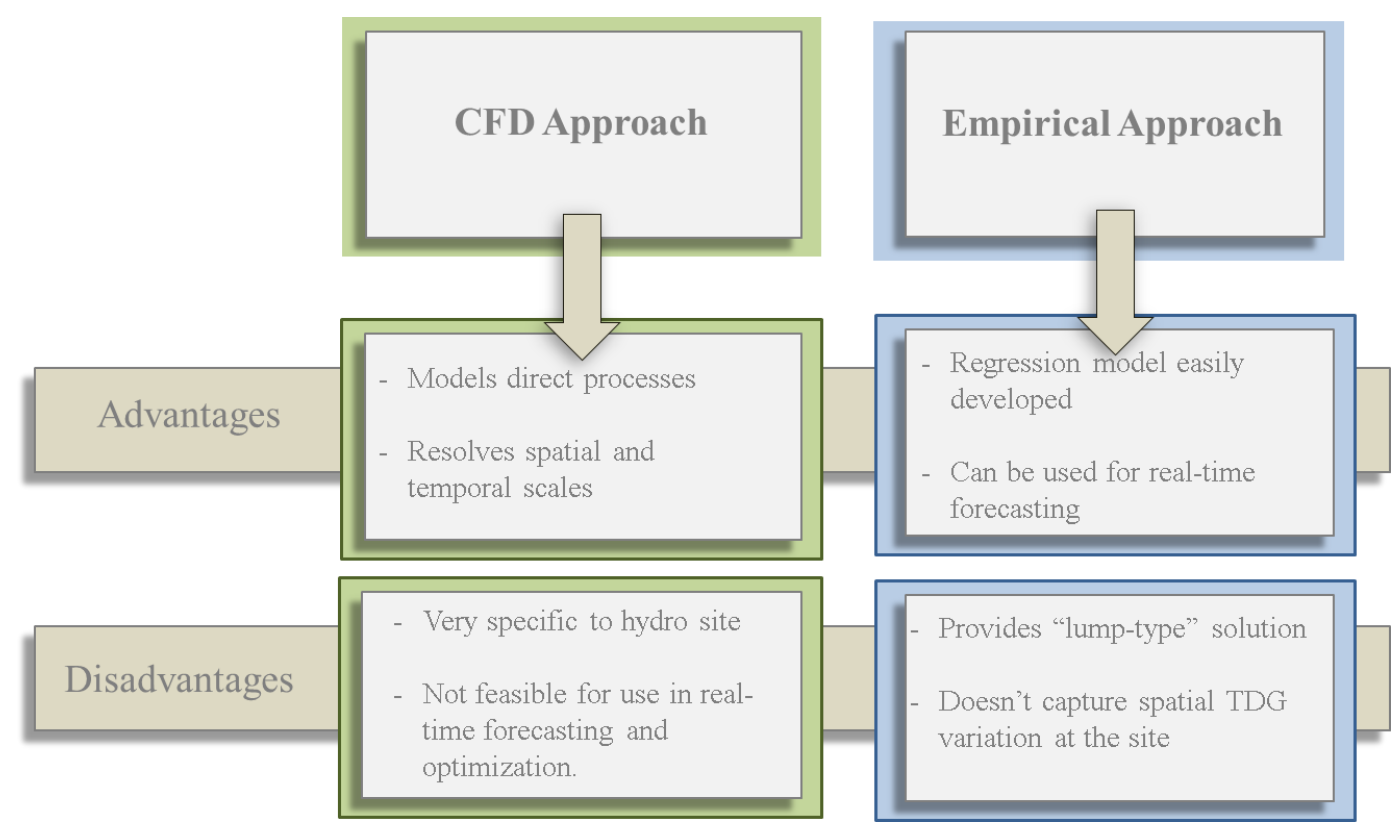

Figure 2 - Advantages and disadvantages associated with direct (CFD) and indirect (empirical) modeling approaches for predicting TDG levels.

To adequately plan and efficiently operate the hydro system with respect to its demands and downstream TDG levels, the TDG modeling tool developed for integration into RiverWare will allow an operator to determine a system-wide operational strategy that will maximize hydropower generation while minimize downstream TDG levels. The extent of this project's goal of predicting and minimizing TDG within the framework of hydro operations modeled in RiverWare relies on accomplishing the following three major steps (see Figure 3): 1) TDG prediction methodology development, 2) calibration and validation of the methodology, and 3) incorporating the TDG predictive methodology into RiverWare. 


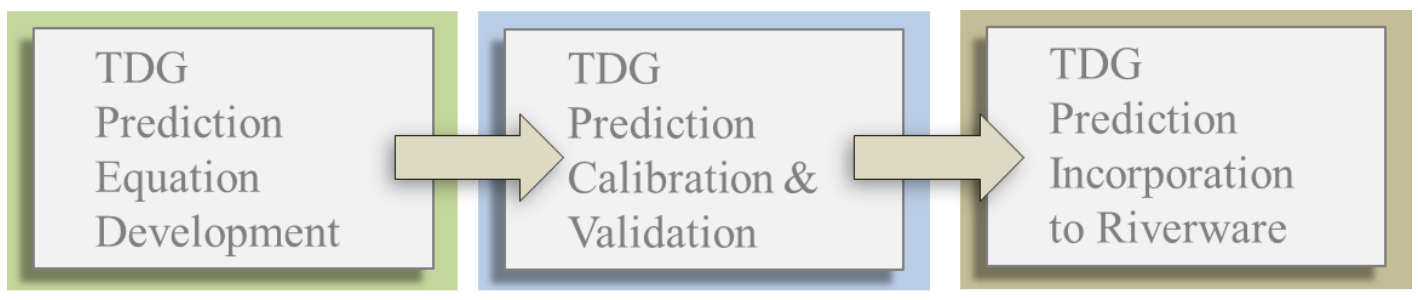

Figure 3 - Project development of TDG prediction based techniques employed in a reservoir system modeling tool.

\subsection{TDG PREDICTION}

The TDG prediction methodology is based upon the development of an approach that can easily and quickly predict TDG since it will be incorporated into a real-time forecasting model. The simplified TDG prediction equations are developed with respect to two primary variables - the background TDG levels located upstream of the dam and the TDG production processes on the downstream section of the dam. Upstream TDG concentration serves as a known input, and is typically measured in the forebay on the upstream face of the dam. The production of TDG in the tailrace, represented as a mixed quantity, is governed by the following physically controlled processes (Figure 4):

- Powerhouse Flow

- Spillway Flow

- Tailwater Depth

- Calculated Entrainment of Powerhouse Flow into Spillway Flow

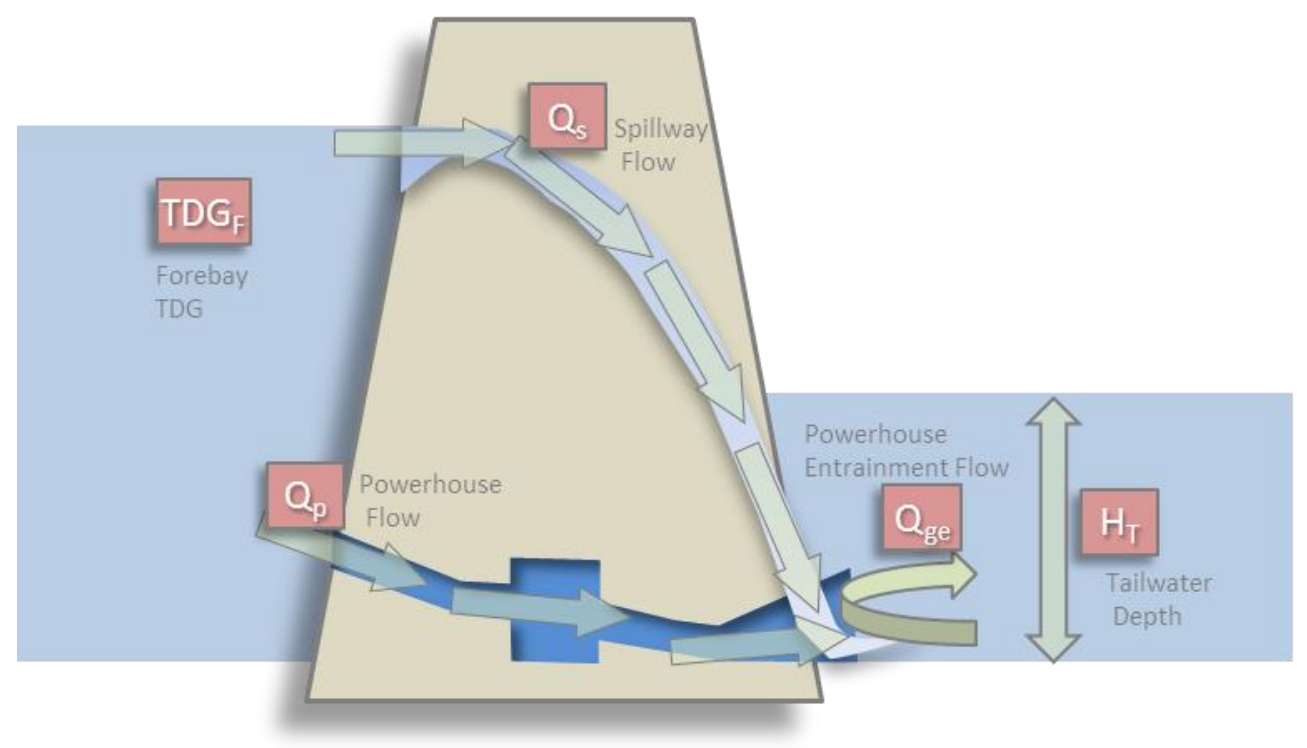

Figure 4 - Physical processes of hydro and dam operation governing the development of the TDG predictive methodology. 
The majority of the processes included in Figure 4 are controlled by hydro operations, with the exception of the background TDG (located upstream). However, upstream TDG levels are affected to some degree by the operation and control of facilities further upstream.

The simplified equation (Eq. 1) for the prediction of TDG uptake at a hydroelectric facility is given as

$$
T D G_{T}=100 X_{S}\left(1+\frac{\rho g H_{T}}{2 P_{a t m}}\right) b_{2}+X_{g} T D G_{F}
$$

where (all in SI units):

$$
\begin{aligned}
& X_{s}=\frac{\left(Q_{S}+Q_{g e}\right)}{\left(Q_{S}+Q_{P}\right)} \\
& X_{g}=\frac{\left(Q_{P}-Q_{g e}\right)}{\left(Q_{S}+Q_{P}\right)} \\
& Q_{g e}=\min \left[Q_{p},\left(b_{1} Q_{s}+b_{3}\right)\right]
\end{aligned}
$$

$Q_{S}$ and $Q_{P}$ are the spillway and powerhouse flows, respectively, $Q_{g e}$ refers to the amount of powerhouse flow entrained into the spillway region by physical hydraulic processes, and the coefficients $b_{1}, b_{2}$, and $b_{3}$ are derived through calibration and validation with measured data at each project.

This set of equations predicting tailrace TDG $\left(T D G_{T}\right)$, given as a percentage, is developed by considering the combined weighted effects of spillway and powerhouse flows on two quantities - local saturation efficiency as a function of tailwater depth, and forebay TDG levels (upstream of the hydroelectric facility). The local saturation efficiency is calculated as the ratio of water pressure experienced by bubbles in the tailrace, taken as the average bubble depth (one-half the tailwater depth, or $H_{T} / 2$ ) multiplied by unit weight $(\rho g)$, to atmospheric pressure, $P_{a t m}$. Projects with a deeper tailrace will exhibit higher saturation efficiencies as bubbles can descend further and experience greater pressures. Forebay TDG $\left(T D G_{F}\right)$ is a model input obtained through field measurements at each project.

The weighted contributions of local saturation efficiency and forebay TDG are determined by considering the volume of powerhouse flow entrained into the spillway region. The assumption is that TDG uptake is flow limited as opposed to bubble limited; as more powerhouse flow is entrained into the spillway region (high TDG production region), the proportion of overall flow that experiences an uptake in TDG will increase. The volume of powerhouse flow entrained into the spillway, $Q_{g e}$, is assumed to increase linearly with spillway flow until all powerhouse flows are entrained. In mathematical form, as $Q_{g e}$ approaches $Q_{P}$, the local saturation efficiency becomes the determining factor in TDG uptake. An additional assumption is that no TDG uptake occurs in the powerhouse - if there is no spill the model will equate downstream TDG to upstream TDG. The dynamics of $Q_{g e}$ are determined by the model coefficients $b_{1}$ and $b_{3}$. 
The relationship between upstream and downstream TDG with respect to the spillway and powerhouse flow proportions can be further illustrated by rearranging Eq. 1 as

$$
T D G_{T}=100[\underbrace{\left[\frac{Q_{s}+b_{1} Q_{s}+b_{3}}{Q_{s}+Q_{p}}\right]}_{\mathrm{A}}] \underbrace{1+\frac{P_{T W}}{2 P_{a t m}}}_{\mathrm{B}}] b_{2}+T D G_{F}[\underbrace{\left.\frac{Q_{p}-b_{1} Q_{s}-b_{3}}{Q_{s}+Q_{p}}\right]}_{\mathrm{C}} \text { (Eq. 5) }
$$

where:

A $=$ Weighted contribution of spillway plus powerhouse entrainment flows for adjusting dependency of TDG's production on tailwater depth.

$\mathrm{B}=$ TDG's dependency on tailwater depth as referenced to atmospheric pressure and adjusted by a fitted dissolution efficiency coefficient $\left(b_{2}\right)$.

$\mathrm{C}=$ Weighted contributions of the difference between the powerhouse and its entrainment flows used to adjust the fraction of forebay TDG transferred downstream.

\subsection{DATA PROCESSING AND ASSUMPTIONS}

\subsubsection{Data Collection and Preliminary Filtering}

Hourly data were collected from the USACE Northwestern Division's Dataquery system and Historical Water Quality Reports (HWQR) online database. The Dataquery system includes eight of the Columbia River Basin dams, while the HWQR database only includes Grand Coulee and Chief Joseph dams. The data are derived from identical water quality gauges, and include measurements of TDG, water temperature, and elevation at both headwater and tailwater locations, as well as flow and energy measurements at the dams.

For the projects included in the HWQR database, TDG and water temperature data from both Dataquery and HWQR were consolidated, with preference given to Dataquery when data were available from both sources. Hourly data were available from 2004 to 2012 to ensure an adequate supply of data for model development and calibration. The following table identifies hourly records collected from the Dataquery and HWQR databases: 
Table 1 - Hourly data collected from USACE databases for seven Columbia River Basin projects.

\begin{tabular}{|c|c|c|c|c|c|c|c|c|}
\hline \multicolumn{2}{|c|}{ Project Name } & $\begin{array}{c}\text { Grand } \\
\text { Coulee }\end{array}$ & $\begin{array}{c}\text { Chief } \\
\text { Joseph }\end{array}$ & Wells & $\begin{array}{c}\text { Rocky } \\
\text { Reach }\end{array}$ & $\begin{array}{c}\text { Rock } \\
\text { Island }\end{array}$ & Wanapum & $\begin{array}{c}\text { Priest } \\
\text { Rapids }\end{array}$ \\
\hline \multirow{3}{*}{$\begin{array}{c}\text { Head } \\
\text { water }\end{array}$} & \% TDG & $\checkmark$ & $\checkmark$ & $\checkmark$ & $\checkmark$ & $\checkmark$ & $\checkmark$ & $\checkmark$ \\
\cline { 2 - 9 } & Water Temp & $\checkmark$ & $\checkmark$ & $\checkmark$ & $\checkmark$ & $\checkmark$ & $\checkmark$ & $\checkmark$ \\
\cline { 2 - 9 } Tail \\
water & Elevation & $\checkmark$ & $\checkmark$ & $\checkmark$ & $\checkmark$ & $\checkmark$ & $\checkmark$ & $\checkmark$ \\
\cline { 2 - 9 } & Water Temp & $\checkmark$ & $\checkmark$ & $\checkmark$ & $\checkmark$ & $\checkmark$ & $\checkmark$ & $\checkmark$ \\
\cline { 2 - 9 } & Elevation & $\checkmark$ & $\checkmark$ & $\checkmark$ & $\checkmark$ & $\checkmark$ & $\checkmark$ & $\checkmark$ \\
\hline \multirow{4}{*}{ Flows } & Gen Flow & $\checkmark$ & $\checkmark$ & $\checkmark$ & $\checkmark$ & $\checkmark$ & $\checkmark$ & $\checkmark$ \\
\cline { 2 - 9 } & Spill Flow & $\checkmark$ & $\checkmark$ & $\checkmark$ & $\checkmark$ & $\checkmark$ & $\checkmark$ & $\checkmark$ \\
\cline { 2 - 9 } & Misc. Flow & $\checkmark$ & $\checkmark$ & - & - & - & - & - \\
\cline { 2 - 9 } & Tot Flow & $\checkmark$ & $\checkmark$ & $\checkmark$ & $\checkmark$ & $\checkmark$ & $\checkmark$ & $\checkmark$ \\
\hline \multirow{2}{*}{ Energy } & Generated & - & $\checkmark$ & $\checkmark$ & $\checkmark$ & $\checkmark$ & $\checkmark$ & $\checkmark$ \\
\cline { 2 - 9 } & Used & - & $\checkmark$ & $\checkmark$ & $\checkmark$ & $\checkmark$ & $\checkmark$ & $\checkmark$ \\
\hline \multicolumn{2}{|c|}{ Source* } & Type 1 & Type 1 & Type 2 & Type 2 & Type 2 & Type 2 & Type 2 \\
\hline
\end{tabular}

*For Type 1 sources, TDG and water temp data came from the Dataquery system; elevation and flow came from the Historical Water Quality Database. For Type 2, all data was obtained from the Dataquery system.

Hourly records including energy and miscellaneous flow were not available for some projects in the databases; however, these hourly records were not essential to proceed with model development. In contrast, Dataquery contained corrupt tailwater TDG data for Rocky Reach and Rock Island, which are essential to modeling TDG formation at dams. Chelan County PUD, owner and operator of the Rocky Reach and Rock Island projects, was contacted and agreed to provide the missing hourly TDG data for the dams.

Excel spreadsheets were created for each of the hydroelectric projects, with hourly records from the USACE databases included. Initial data screening included processing missing information and removing outlying water temperature and TDG data. Water temperature values below $32^{\circ} \mathrm{F}$ and above $80^{\circ} \mathrm{F}$ were removed. Additionally, TDG values below 50 and above 300 were removed. Further screening was also completed when the presence of invalid data was clear. For example, during a period in October 2004, the USACE Dataquery system provided TDG saturation numbers for Grand Coulee forebay exceeding $10,000 \%$.

Unit spill operation data were obtained using a variety of methods. For Grand Coulee, data were available for the number of drum gates and outlet work conduits open on an hourly basis. However, the data did not specify which drum gates and outlet works conduits were open or the flow rate through individual gates. Using the total spill (available from the USACE databases) in conjunction with the outlet works rating curve and headwater elevation, it is possible to calculate unit spill for the majority of spill scenarios. ORNL and IIHR communicated with Chelan County PUD and had success obtaining unit spill operation at Rock Island Dam. 


\subsubsection{Project Specific Data Filtering and Assumptions}

After all data was obtained and initially filtered for missing dates and outliers, a more specific filter was applied to each site to remove data that is physically inconsistent with reality or unfeasible based on operational parameters ranges. For example, this includes but is not limited to flow, tailrace, and reservoir elevation parameters that are outside the typical ranges of normal and expected operations.

\subsection{CALIBRATION AND VALIDATION}

Data for each of the projects contain all necessary flows and downstream TDG measurements on an hourly basis beginning ${ }^{1}$ in 2004 and extending through various years to 2012 depending on the project). For each of the project sites, model calibration and validation to determine the three coefficients, $b_{1}, b_{2}$, and $b_{3}$ is performed by minimizing the Root Mean Square Error (RMSE) between the measured and predicted TDG values. The Root Mean Square Error (Eq. 6) is the percentage of the average error of the predicted $(P)$ results relative to the measured $(M)$ dataset. $^{2}$

$$
\operatorname{RMSE}(\%)=\frac{\sqrt{\frac{1}{n} \sum_{i=1}^{n}\left(P_{i}-M_{i}\right)^{2}}}{\frac{1}{n} \sum_{i=1}^{n} M_{i}} \cdot 100
$$

Constraints are imposed on the coefficients for the calibration and validation such that the components of the TDG prediction equation (Eq. 1) are realistically representative. The constraints imposed during calibration and validation are:

- $\quad b_{2}$ must be greater than zero to ensure that the TDG production component in Eq. 1 is a positive quantity,

- the entrainment term $Q_{g e}$ in Eq. 4 must be greater than zero to ensure powerhouse entrainment flows are always positive,

- For "no-spill" conditions, $T D G_{T}$ is a function of $T D G_{F}$ and is defined as follows:

If $Q_{S}=0$ :

$$
T D G_{T}=\left[T D G_{F}+c_{1}\right]
$$

where $c_{1}$ is the average measured TDG uptake during all "no-spill" conditions at a project.

\footnotetext{
1 Chief Joseph data begins in 2009, however, due to the addition of deflectors in 2009; data for 2010 through 2012 is used to maintain consistency in analysis.

2 Note that the RMSE presented herein is the percentage error of the percent TDG.
} 
Table 2 - Constant coefficients representing TDG reuptake in reference to background reservoir TDG levels.

\begin{tabular}{l|c} 
Project & $\boldsymbol{c}_{\mathbf{1}(\%)}$ \\
\hline \hline Grand Coulee & -0.9 \\
\hline Chief Joseph & 0.08 \\
\hline Wells & 0.5 \\
\hline Rocky Reach & -0.56 \\
\hline Rock Island* & 0 \\
\hline Wanapum & 0.78 \\
\hline Priest Rapids & 0.1
\end{tabular}

*For Rock Island: If TDG $G_{F}<102, c_{1}=4.98$.

For purposes of calculating the tailwater depth, $H_{T}$, in Eq. 1, the following tailrace bottom elevations are used:

Table 3 - Constant coefficients representing TDG reuptake in reference to background reservoir TDG levels.

\begin{tabular}{l|c} 
& Tailrace Floor Elevations $(\boldsymbol{f t})$ \\
\hline \hline Grand Coulee & 900 \\
\hline Chief Joseph & 743 \\
\hline Wells & 600 \\
\hline Rocky Reach & 585 \\
\hline Rock Island & 550 \\
\hline Wanapum & 456 \\
\hline Priest Rapids & 387
\end{tabular}

To quantitatively compare the measured $(M)$ and predicted $(P)$ data sets, some common performance metrics are used in addition to regression scatter plots of calibrated and validated data sets. Metrics used to assess the model's performance and quality of the coefficient calibration are the root-mean-squareerror (RMSE) defined earlier in Eq. 6 and the correlation coefficient $R^{2}$ defined in Eq. 8 which is the determination of the strength of the linear relationship between the predicted and observed values.

$$
R=\frac{n \sum_{i=1}^{n}\left(M_{i} P_{i}\right)-\sum_{i=1}^{n} M_{i} \sum_{I=1}^{n} P_{i}}{\sqrt{\left[n \sum_{i=1}^{n}\left(M_{i}^{2}\right)-\left(\sum_{i=1}^{n} M_{i}\right)^{2}\right]\left[n \sum_{i=1}^{n}\left(P_{i}^{2}\right)-\left(\sum_{i=1}^{n} P_{i}\right)^{2}\right]}}
$$




\subsection{RESULTS}

The results of the calibration and validation are depicted in Table 4 below. Graphical comparisons of each of the sites (color coded by spillway flow discharge) are shown in Figures 5 through 11 as scatter plots. Time series of the spill and powerhouse flowrates along with measured and simulated TDG levels for both the calibrated and validated cases are shown in Figures 12 through 18.

Table 4 - Coefficients and performance statistics for TDG predictions.

\begin{tabular}{||l|ccccc|cc||}
\hline \multirow{2}{*}{ Project Site: } & \multicolumn{4}{|c|}{ Calibrated with 2008-2010 data } & \multicolumn{2}{c|}{$\begin{array}{c}\text { Validated with } \\
\text { 2004-2012 data }\end{array}$} \\
\cline { 2 - 9 } & $b_{1}$ & $b_{2}$ & $b_{3}$ & $R^{2}$ & $R M S E(\%)$ & $R^{2}$ & $R M S E(\%)$ \\
\hline \hline Grand Coulee & 1.089 & 0.562 & 290.5 & 0.793 & 2.33 & 0.997 & 4.15 \\
\hline Chief Joseph & 1.509 & 0.706 & 354.5 & 0.930 & 2.54 & 0.930 & 1.54 \\
\hline Wells & 0.338 & 0.487 & -73.8 & 0.958 & 0.94 & 0.958 & 1.28 \\
\hline Rocky Reach & 1.096 & 0.767 & 263.2 & 0.857 & 1.51 & 0.921 & 1.51 \\
\hline Rock Island & 0.030 & 0.941 & 119.4 & 0.952 & 1.27 & 0.942 & 1.38 \\
\hline Wanapum & 0.298 & 0.784 & 58.8 & 0.932 & 1.69 & 0.930 & 2.05 \\
\hline Priest Rapids & 0.010 & 0.886 & 172.8 & 0.966 & 1.10 & 0.972 & 1.42 \\
\hline
\end{tabular}

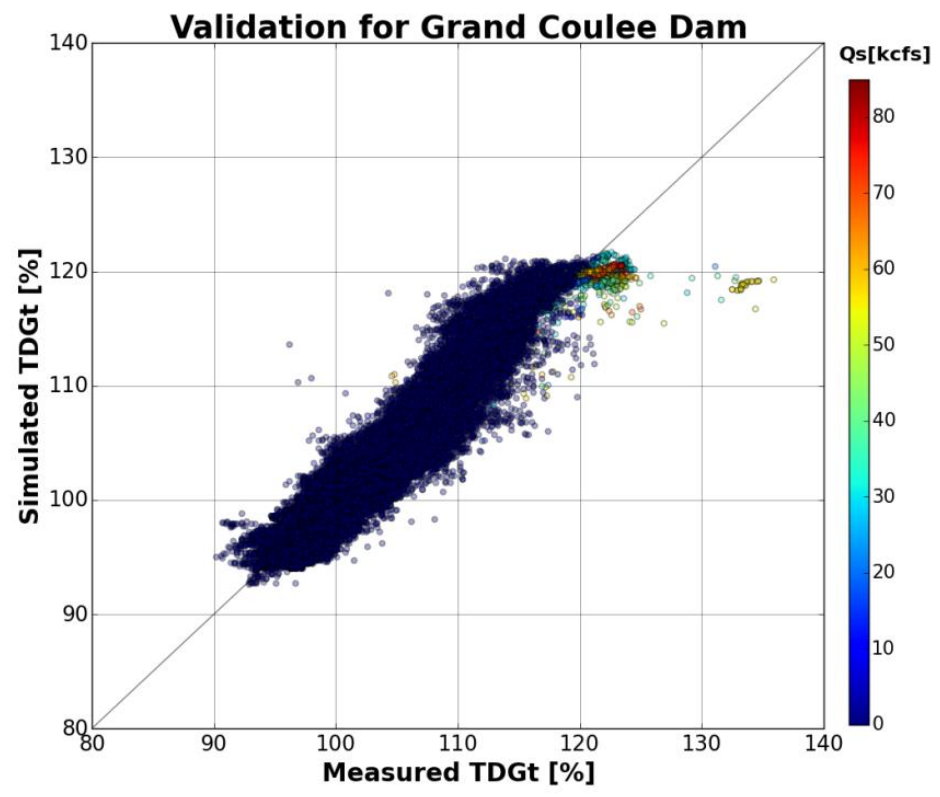

Figure 5-Scatter plot for measured verses simulated TDG levels at the tailrace of Grand Coulee Dam (data points are color coded by spill). 


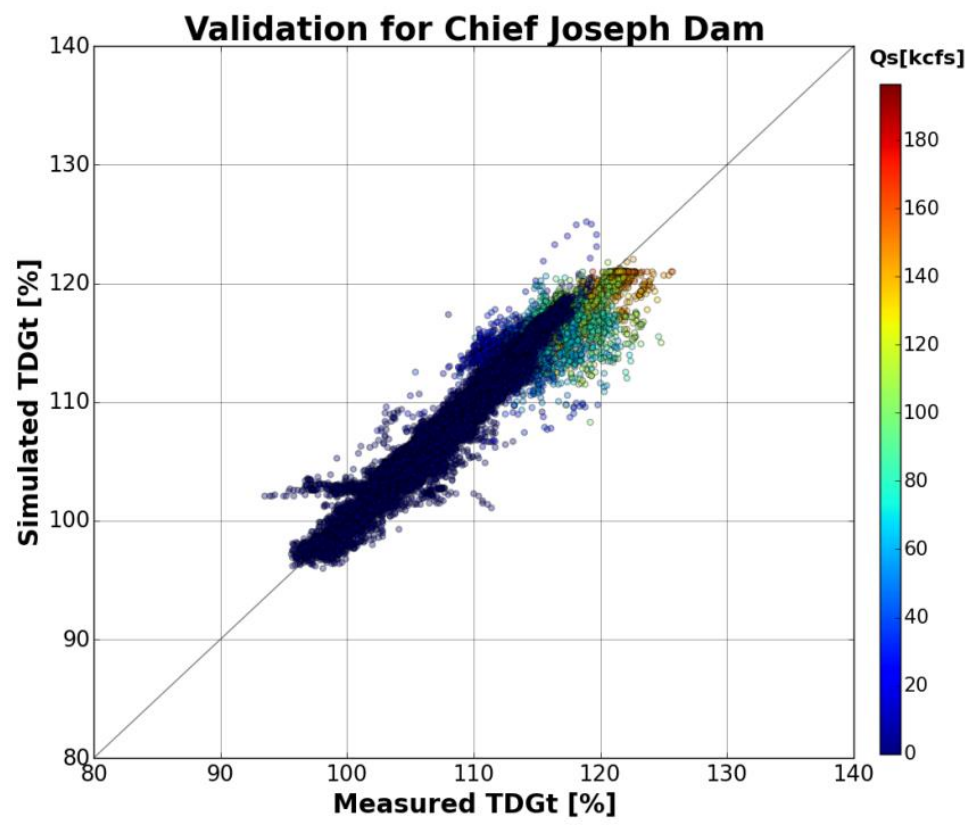

Figure 6-Scatter plot for measured verses simulated TDG levels at the tailrace of Chief Joseph Dam (data points are color coded by spill).

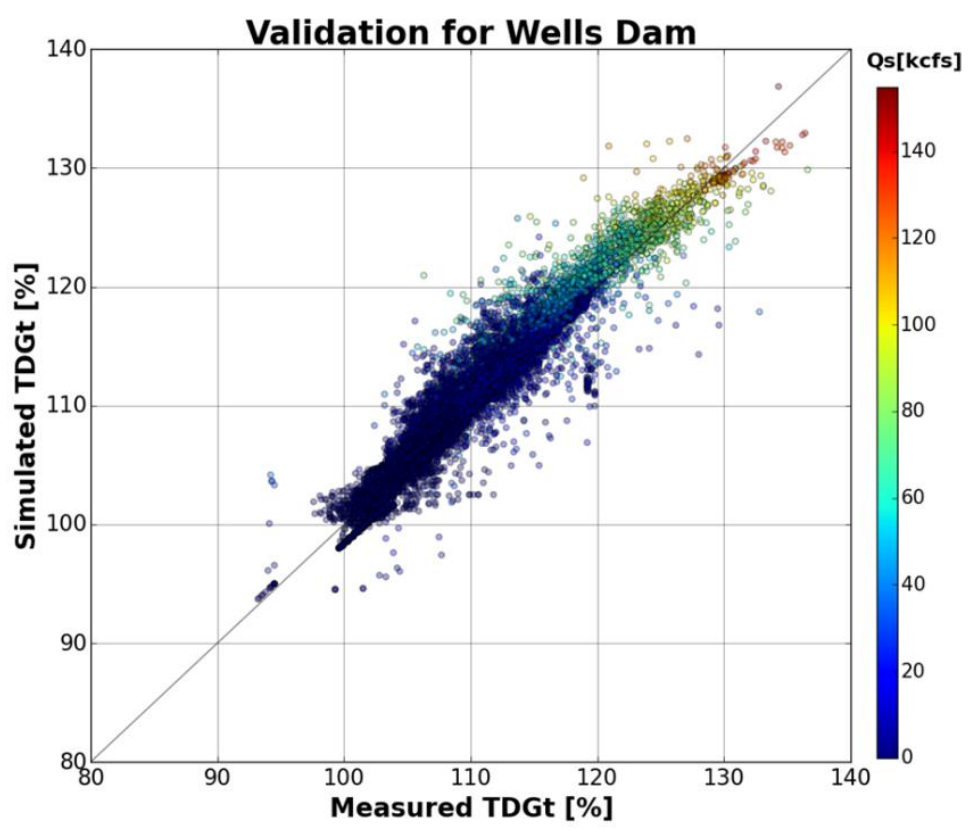

Figure 7 -Scatter plot for measured verses simulated TDG levels at the tailrace of Wells Dam (data points are color coded by spill). 


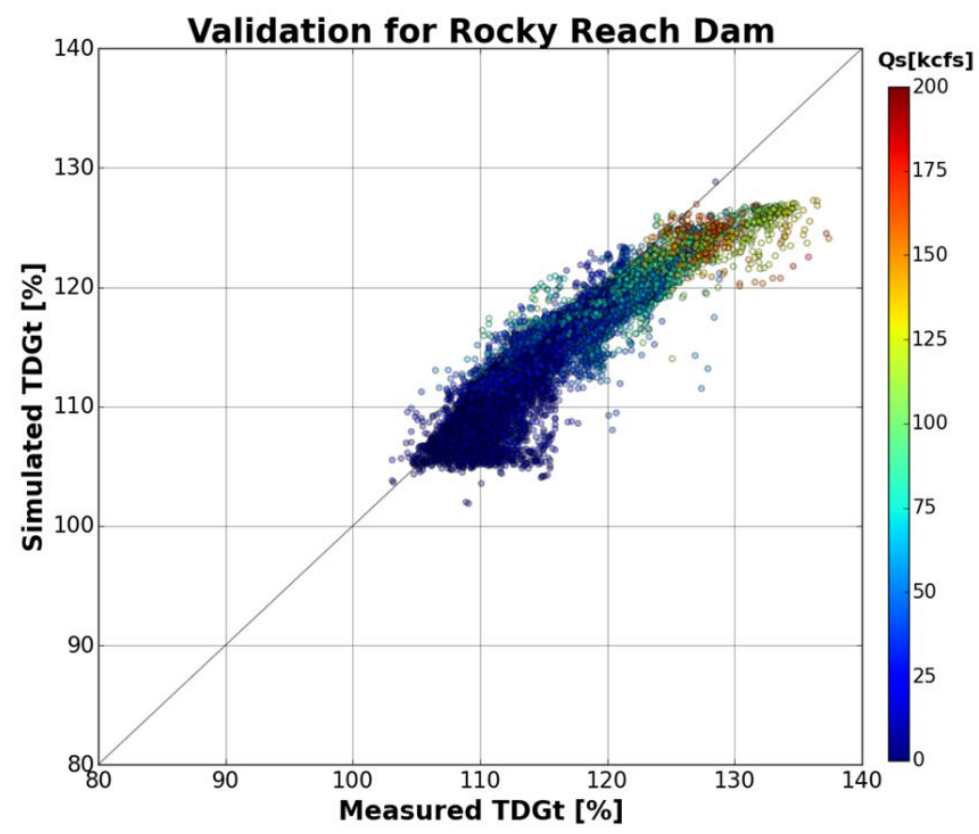

Figure 8-Scatter plot for measured verses simulated TDG levels at the tailrace of Rocky Reach Dam (data points are color coded by spill).

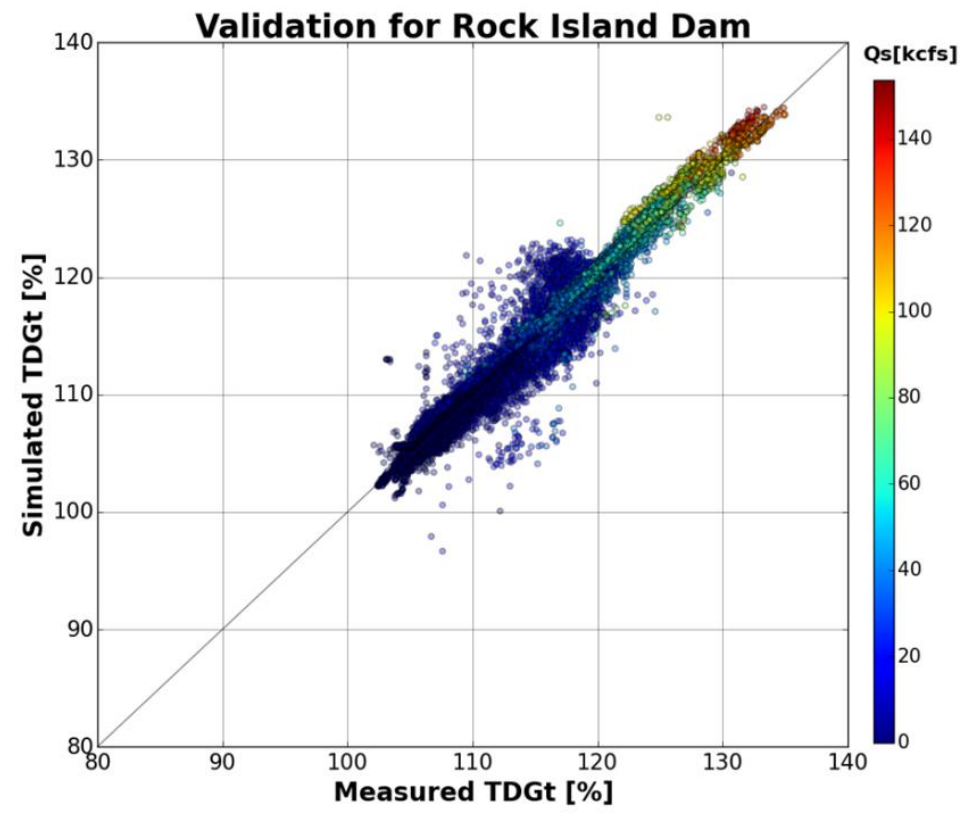

Figure 9-Scatter plot for measured verses simulated TDG levels at the tailrace of Rock Island Dam (data points are color coded by spill). 


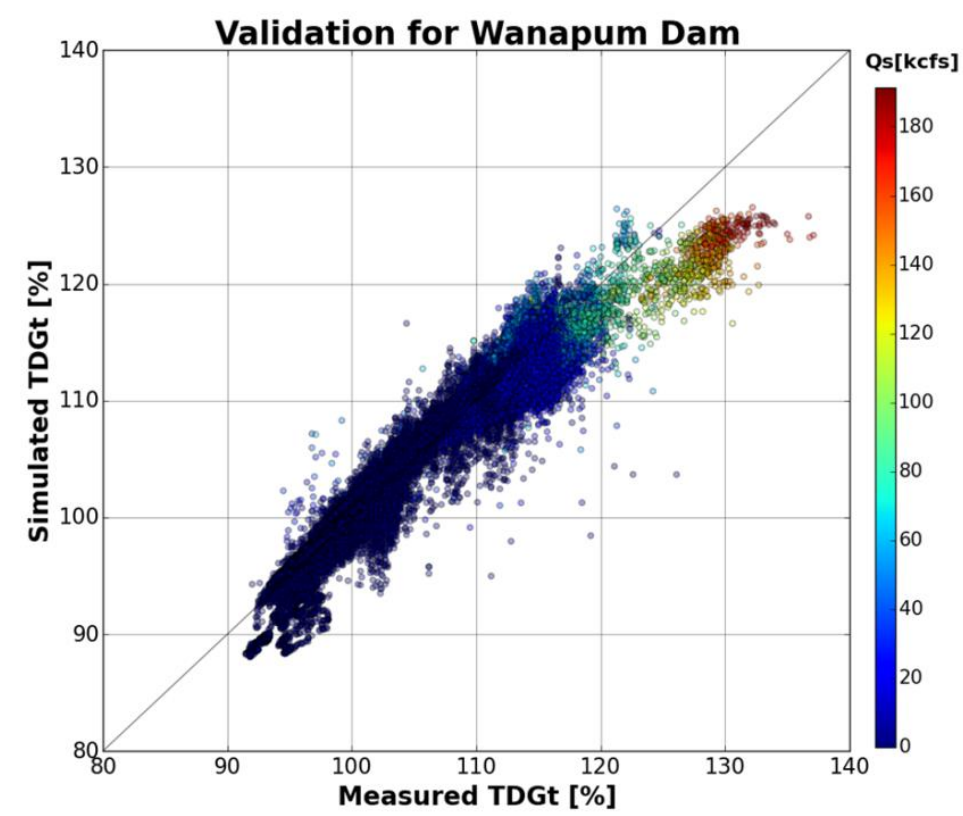

Figure 10 - Scatter plot for measured verses simulated TDG levels at the tailrace of Wanapum Dam (data points are color coded by spill).

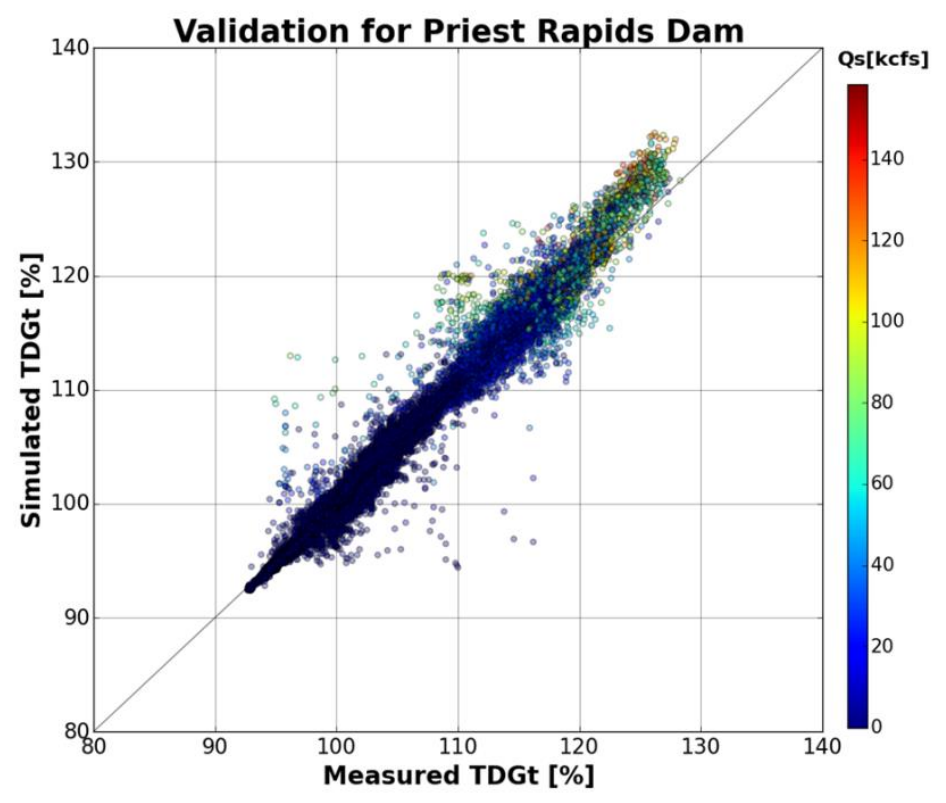

Figure 11 - Scatter plot for measured verses simulated TDG levels at the tailrace of Priest Rapids Dam (data points are color coded by spill). 

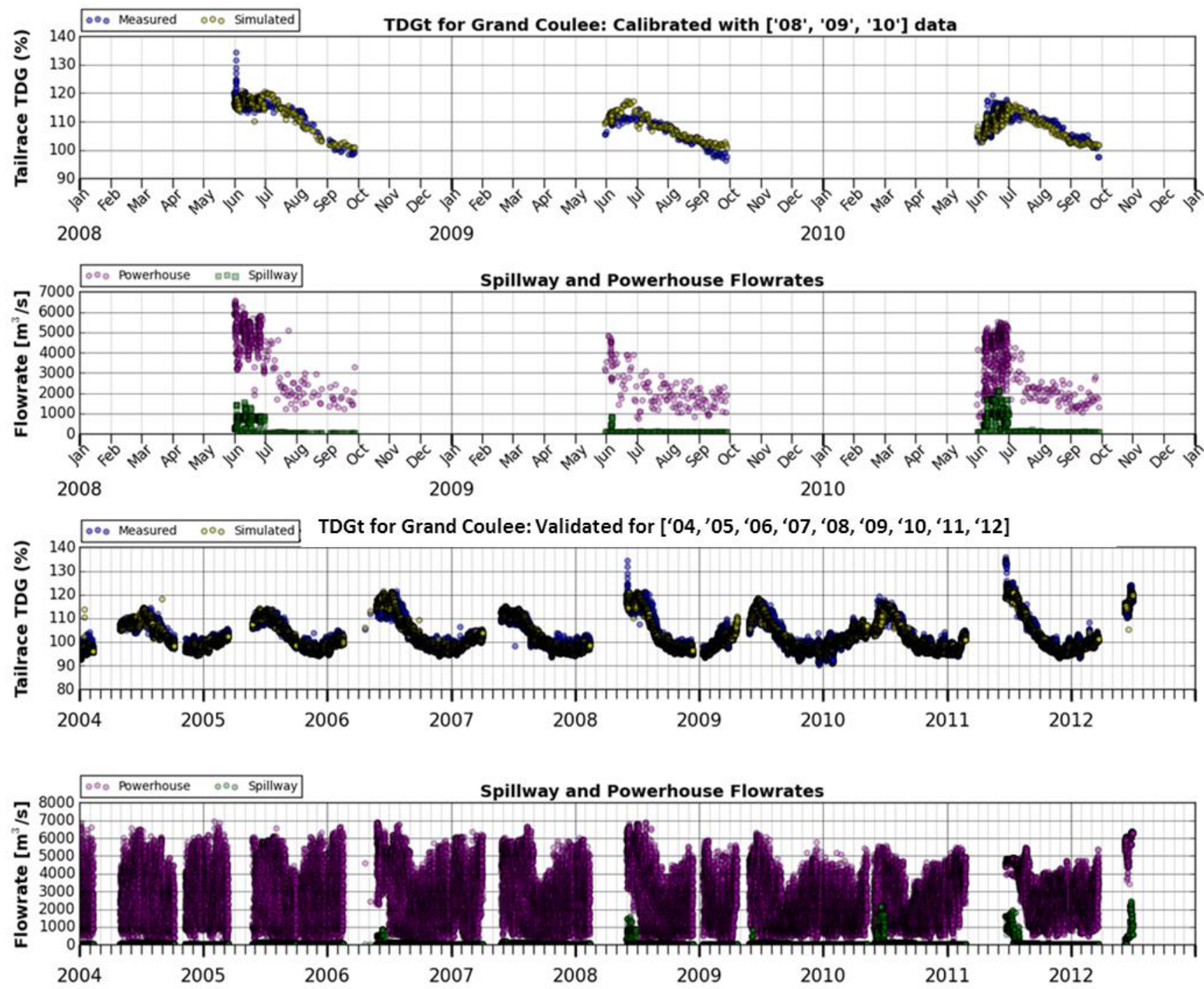

Figure 12 - Time series plots for powerhouse and spillway flows and measured verses simulated TDG levels at the tailrace of Grand Coulee Dam for the calibrated and validated cases. 

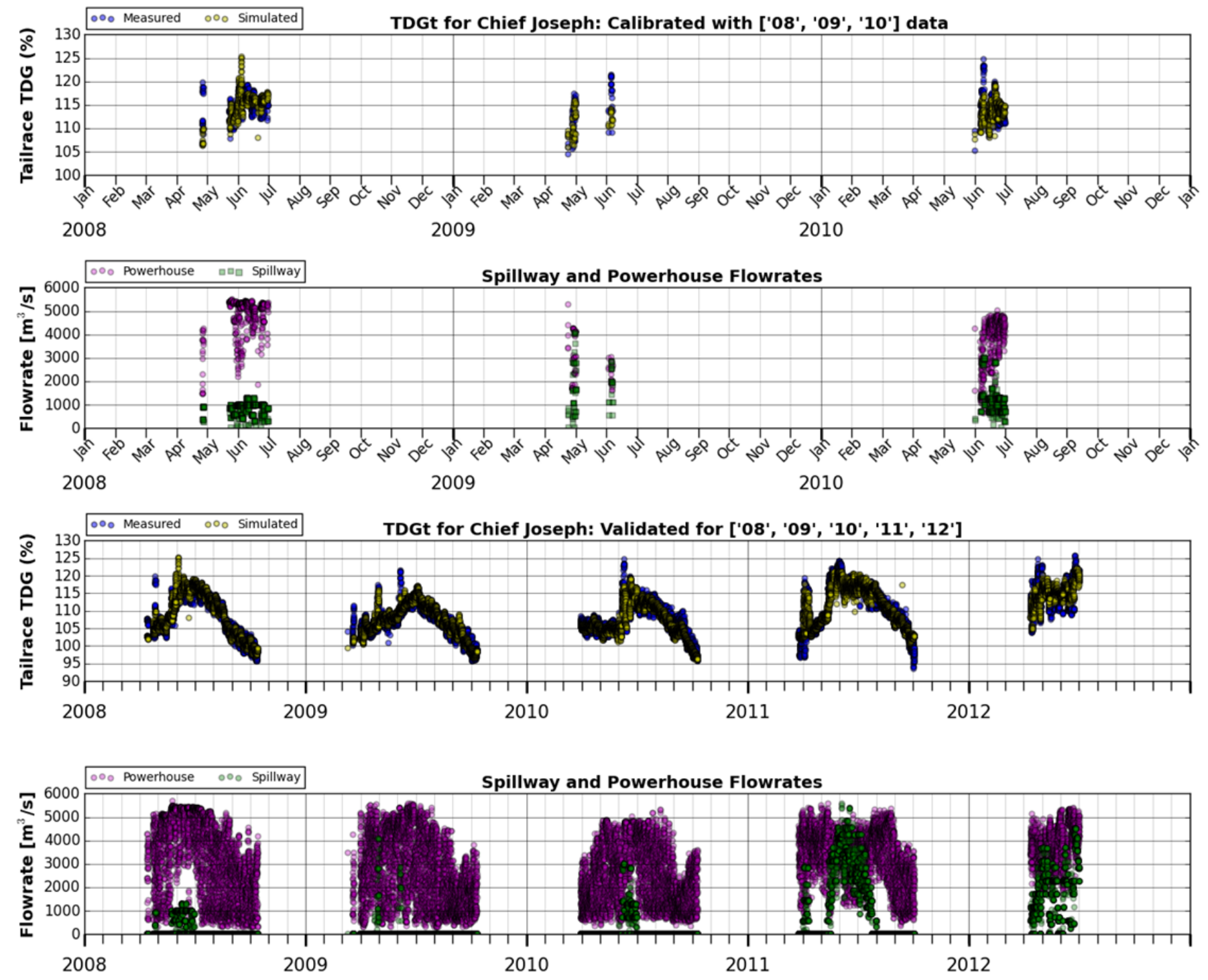

Figure 13 - Time series plots for powerhouse and spillway flows and measured verses simulated TDG levels at the tailrace of Chief Joseph Dam for the calibrated and validated cases. 

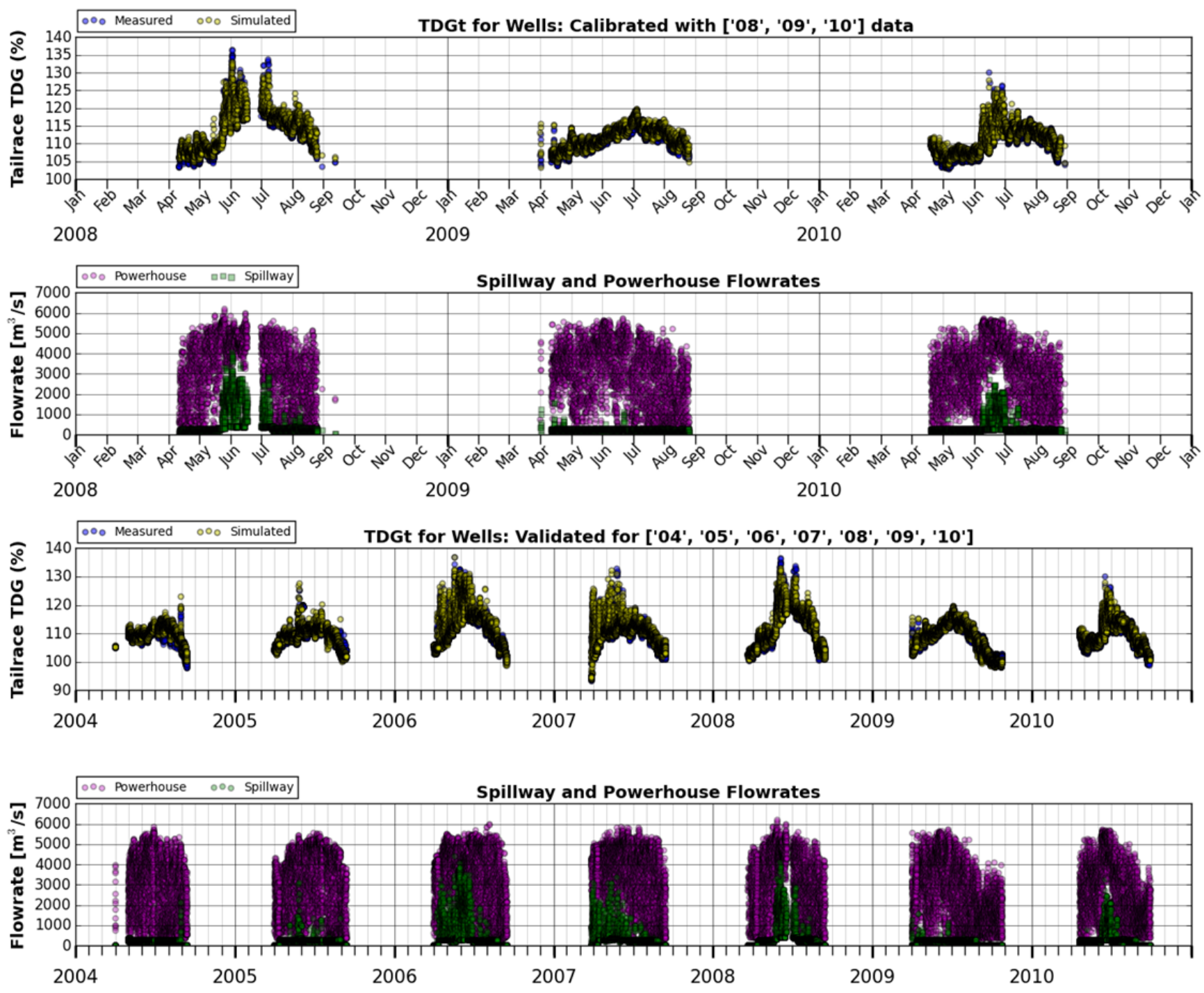

Figure 14 - Time series plots for powerhouse and spillway flows and measured verses simulated TDG levels at the tailrace of Wells Dam for the calibrated and validated cases 

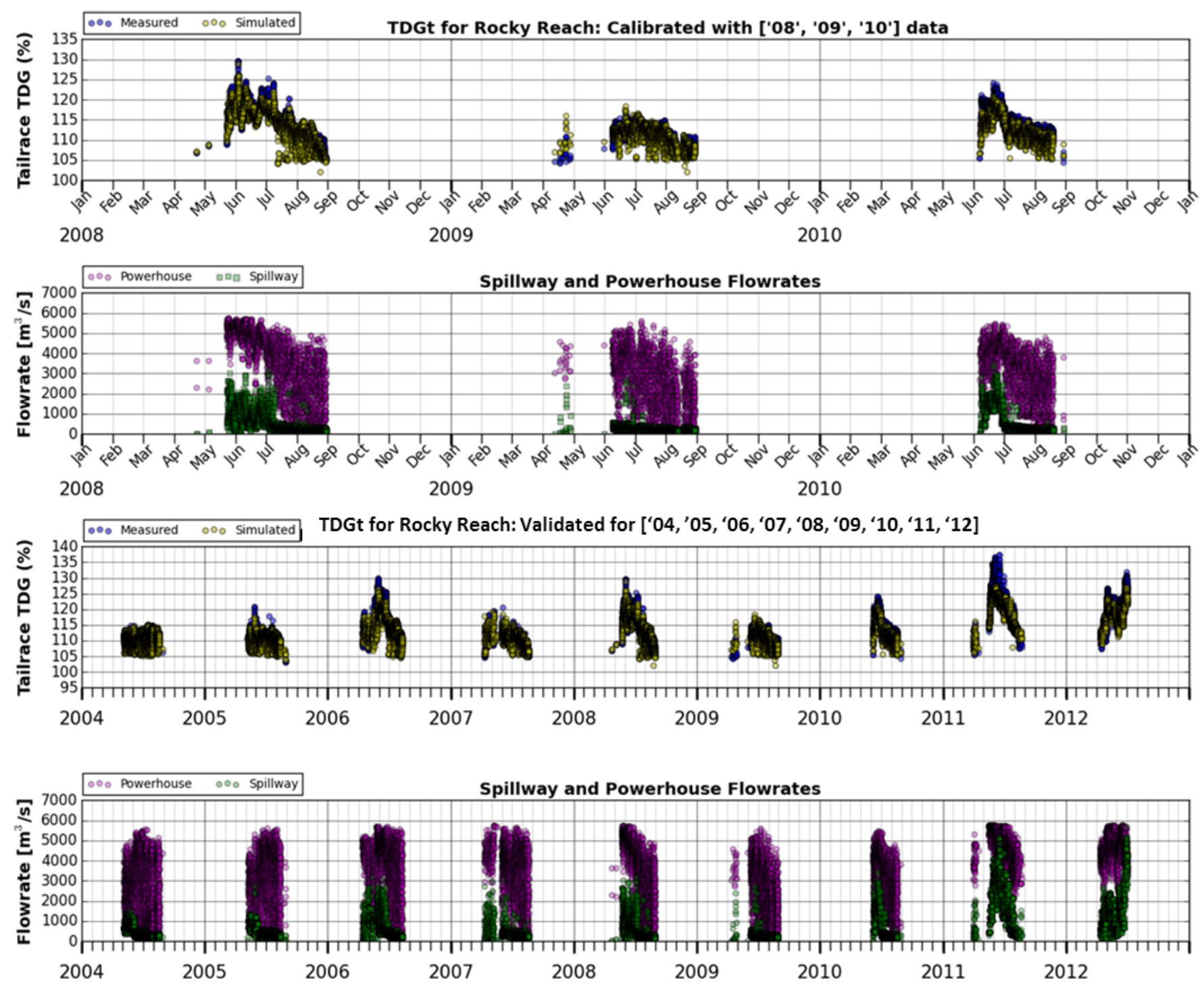

Figure 15 - Time series plots for powerhouse and spillway flows and measured verses simulated TDG levels at the tailrace of Rocky Reach Dam for the calibrated and validated cases 

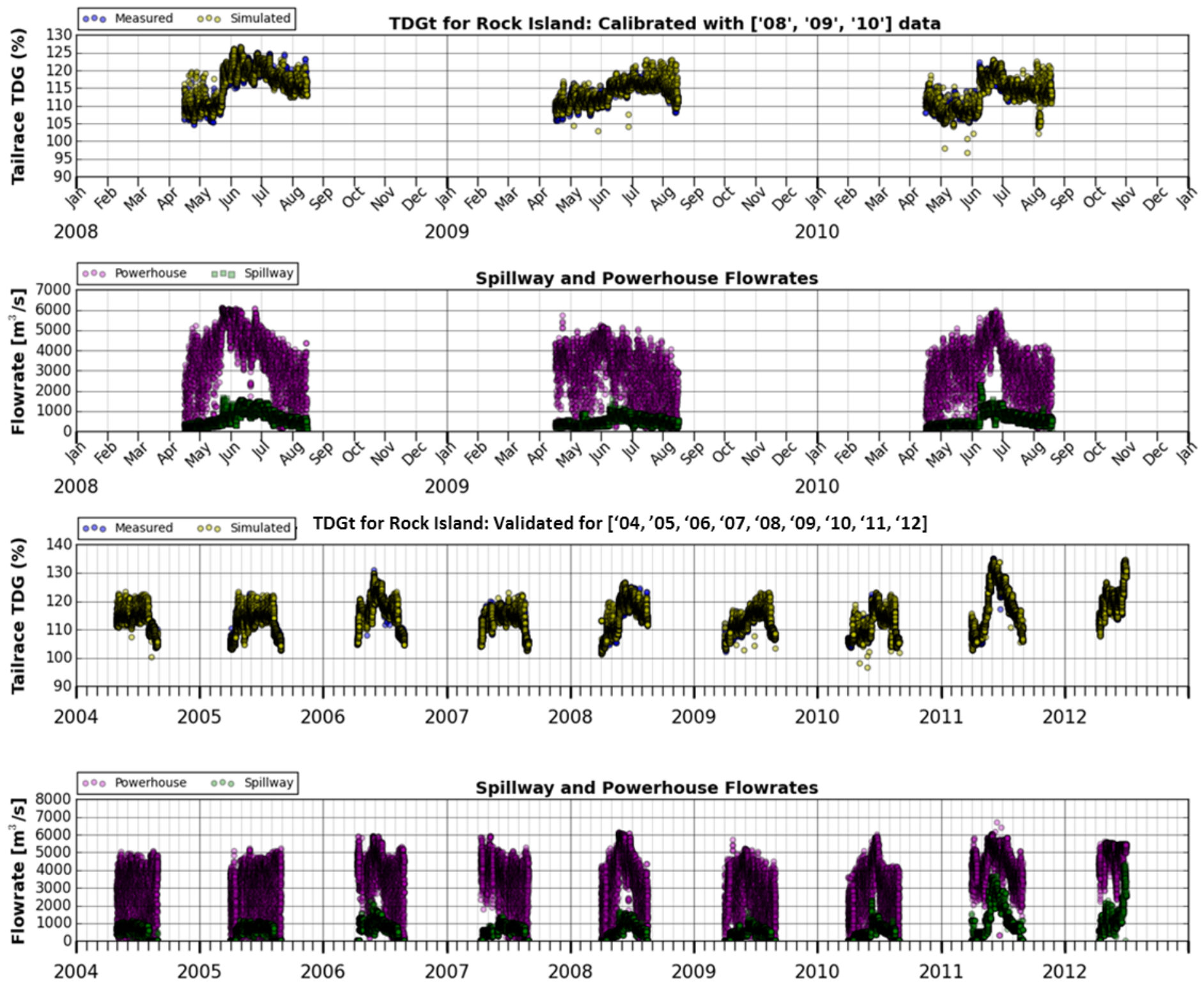

Figure 16 - Time series plots for powerhouse and spillway flows and measured verses simulated TDG levels at the tailrace of Rock Island Dam for the calibrated and validated cases 

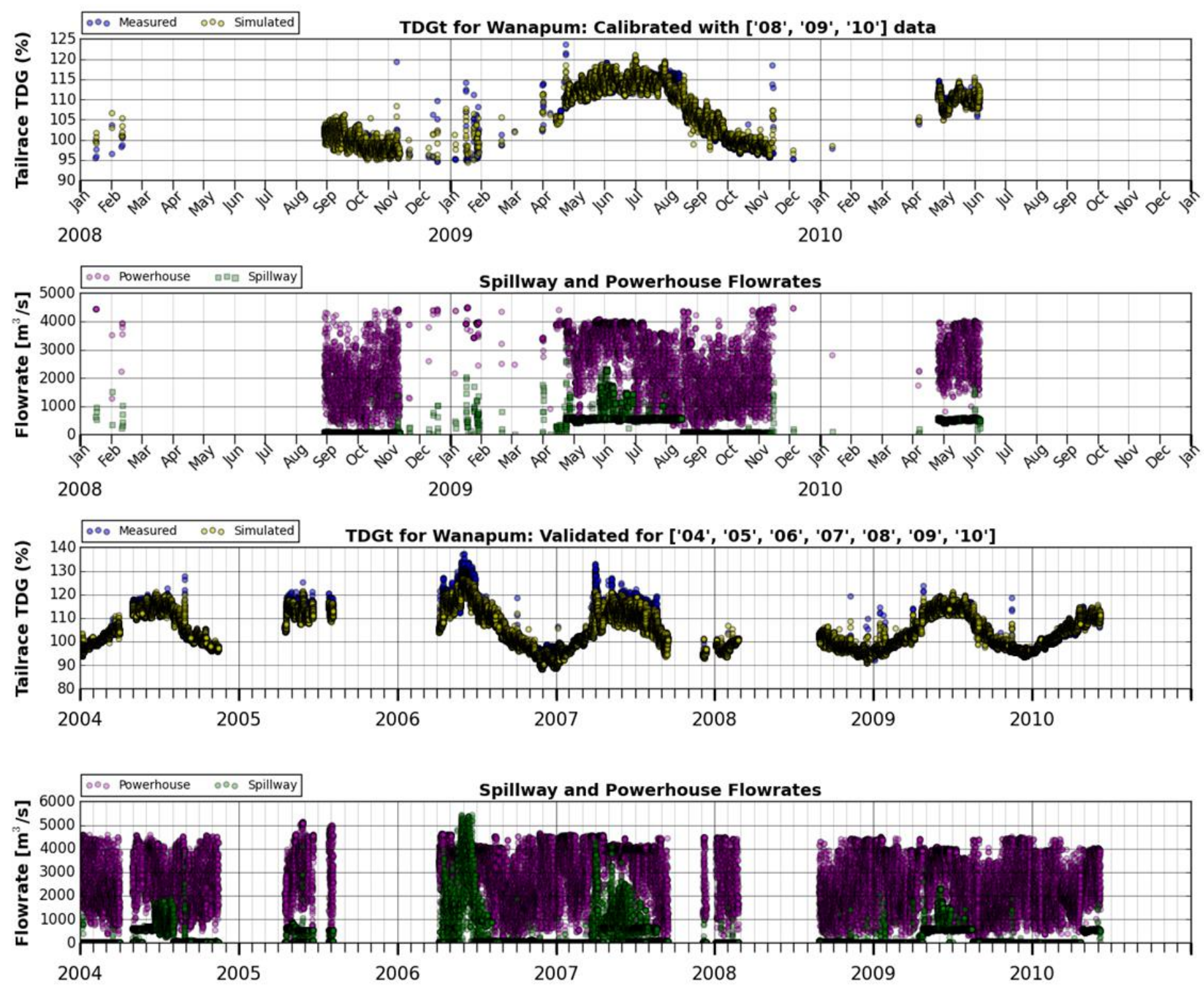

Figure 17 - Time series plots for powerhouse and spillway flows and measured verses simulated TDG levels at the tailrace of Wanapum Dam for the calibrated and validated cases 

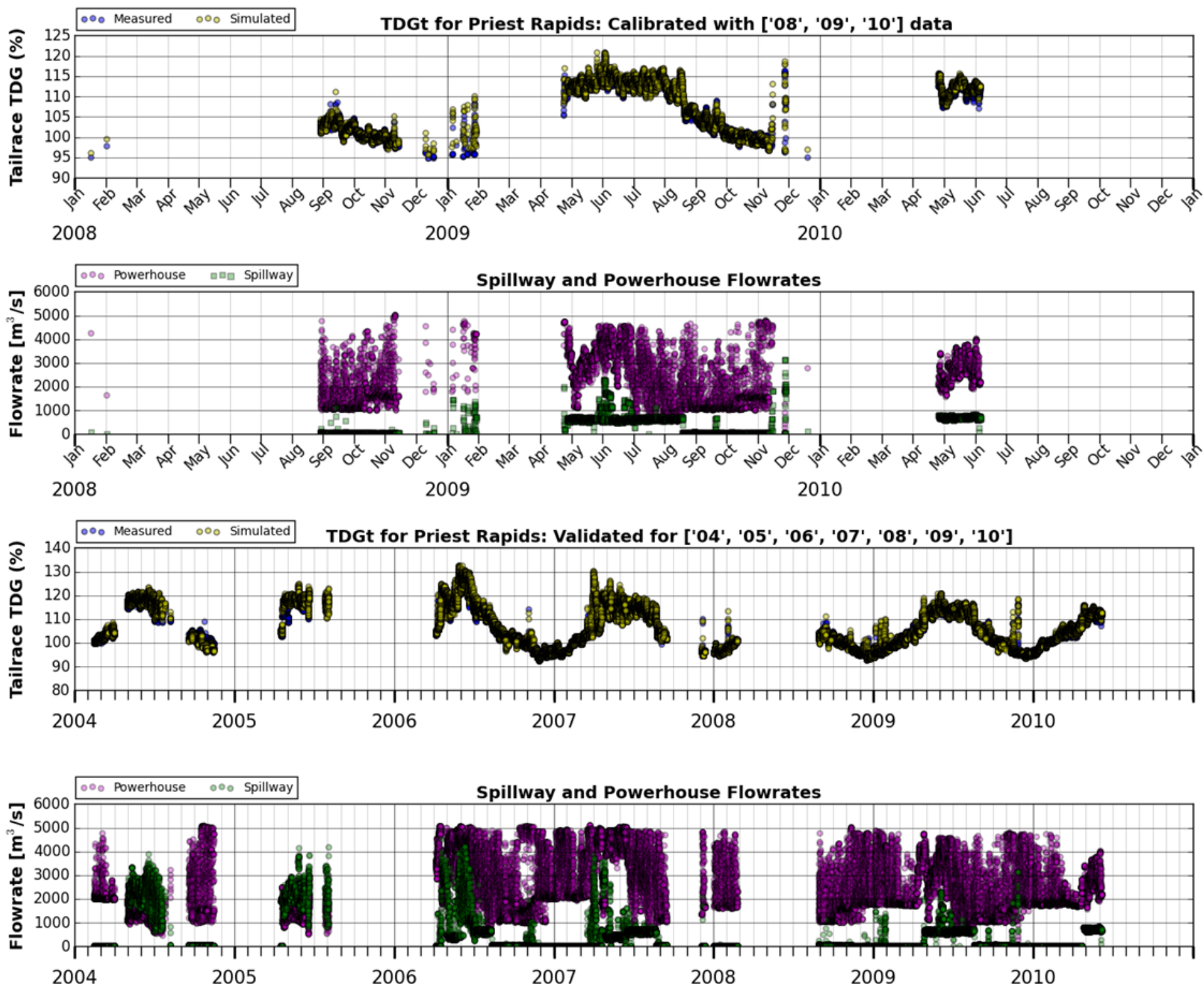

Figure 18 - Time series plots for powerhouse and spillway flows and measured verses simulated TDG levels at the tailrace of Priest Rapids Dam for the calibrated and validated cases 
The validation results presented in summary Table 4 indicate good performance statistics for the model's ability to predict downstream TDG levels at all sites. The scatter plots in Figures 5 through 11 indicate a very good prediction performance on average characterized by the minimum scatter and relatively close fit to the ideal 1:1 prediction line. In most cases, the model does a very good job over the range of spill flows (denoted by colored data) for predicting downstream TDG. This indicates that the two distinctive components of the predictive methodology, i.e., that dominated by spill and that dominated by little to no spill, are performing well. For Grand Coulee, Rocky Reach, and Wanapum Dams, the degree of scatter around the average is consistent for most spill ranges. The scatter plot for Chief Joseph indicates somewhat a higher degree of scatter around the average accompanied by a mild underprediction tendency for medium spill flows in the range of 100,000 to $120,000 \mathrm{cfs}$, but less scatter for the maximum spill flows. Wells, Rock Island, and Priest Rapids scatter plots indicate excellent predictive performance over the entire range of spill flows with relatively minor scatter about the model's average predictive performance. These two sites though do share characteristics of increased scatter around the average for the $110 \%$ to $120 \%$ TDG prediction ranges accompanied by higher proportions of powerhouse to spill flows.

The time-series plots in Figures 12 through 18 provide better insight into some of the trends observed in the scatter plots which represent only an "average" overall performance ability. The projects, Wells, Rock Island, and Priest Rapids in Figures 14, 16, and 18 respectively, all share excellent agreement in TDG prediction. The effect of TDG increase in response to sharp increases of spill is particularly evident for Wells which is characterized by steady powerhouse flows with instances of increased spill. As identified in the scatter plots, the underprediction of TDG for medium spill flows (100,000 to 120,000 cfs) and better agreement for maximum spill flows for Chief Joseph is evident in Figure 13 for the validation case. During 2010, the model slightly underpredicts TDG for medium spill flows, but captures it better in 2011 accompanied by maximum spill flows. The TDG prediction results for Grand Coulee and Rocky Reach Dams in Figures 12 and 15 respectively indicate fairly consistent prediction performance for all spill flows as identified in the scatter plots. For Wanapum dam in Figure 17, the slight underprediction identified in the scatter plot for almost all spill flows is evident and is more significant for higher spill flows.

\subsection{RIVERWARE OPTIMIZATION}

RiverWare is a general river and reservoir modeling tool used for long term planning and forecasting of river and reservoir systems. It utilizes four different solvers to accomplish tasks - simulation, optimization, rule-based simulation, and water accounting solvers. The simulation solver models upstream and downstream physical processes based on input. The optimization solver utilizes linear goal programming to arrive at a solution by solving all timesteps and objects at once. The rule-based simulation utilizes user-specified operating rules to model physical processes. The water accounting solver models ownership, type, and rights.

The process of optimizing the hydro operations of the Mid-Columbia River to minimize TDG levels follows a particular process as outlined in Figure 19. The system is first simulated to solve all unknowns based on known parameters within the model. Next, the system's parameters are adjusted by solving a series of linear programming problems used to minimize and maximize certain system parameters. 
Lastly, rulebased simulation is used to re-adjust parameters based on user-specified operating rules and constraints.

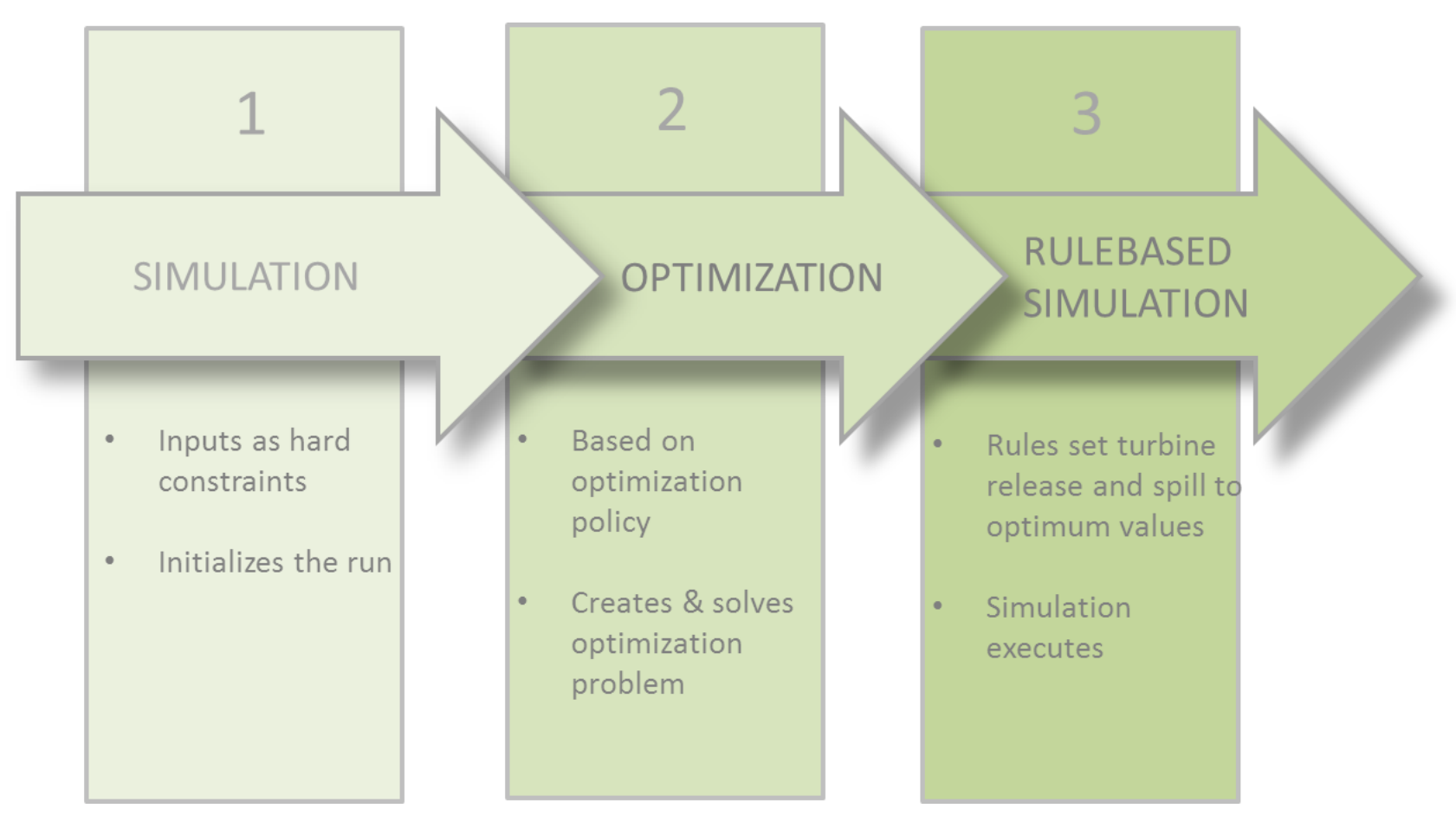

Figure 19 - Process framework of optimization execution within RiverWare

The optimization component in Figure 19 is a preemptive linear goal programming solution, i.e., a series of objectives are optimized in a linear program without sacrificing high priority objectives for lower priority objectives. The individual objective functions are either traditional objective functions or functions that minimize the violation of soft constraints.

The Taylor Series approximations are developed for the TDG predictive equation (Eq. 1). The Taylor series approximation for a single variable $y$ at iteration $\mathrm{i}$ is

$\Delta y=\sum_{j} \frac{\partial y}{\partial x_{j-1}} \Delta x_{j}$

with,

$\Delta y=y_{i}-y_{i-1}$

(Eq. 10)

The optimization proceeds by using the solution values from the previous iteration to evaluate the nonlinear functions and their partial derivatives. These values are used in the equations for the subsequent iteration. The process is initialized by first optimizing without any modeling of the TDG equations. 
A large set of equations of the above form is required to represent the TDG equations. One example is the change in tailwater TDG concentration.

$$
\begin{gathered}
\Delta T D G_{T}=\frac{\partial T D G_{T}}{\partial T D G_{S}} \Delta T D G_{S}+\frac{\partial T D G_{T}}{\partial T D G_{F}} \Delta T D G_{F}+\frac{\partial T D G_{T}}{\partial Q_{S}} \Delta Q_{S}+\cdots \\
\ldots+\frac{\partial T D G_{T}}{\partial Q_{P}} \Delta Q_{P}+\frac{\partial T D G_{T}}{\partial Q_{g e}} \Delta Q_{g e}+\frac{\partial T D G_{T}}{\partial Q} \Delta Q
\end{gathered}
$$

The change variables, i.e. $\Delta$ variables, are also dependent on other change variables including those for tailwater elevation and operating head variables which involve additional partial derivatives. The details for all of the equations are beyond the scope of this paper, but they are similar in form to the equation for tailwater TDG concentration.

To gain a better understanding of the optimization method as well as the development and implementation of the TDG prediction methodology within RiverWare, ORNL staff attended a training seminar at CADSWES on Tuesday, September 1, 2015 in Boulder, CO. The seminar provided an opportunity to gain a "hands-on" experience with initialization and execution of a RiverWare model with respect to TDG prediction.

\section{FUTURE WORK}

The predictive methodology for TDG developed in this project utilizes a specified reservoir TDG to inform the model of the background forebay TDG levels which are used in determining tailrace TDG levels. This is appropriate for predicting tailrace levels for known values and conditions of forebay TDG levels. However, for use in a forecasting application, reservoir forebay TDG levels are unknown for future time periods and must be forecast based on river hydrodynamics and the physics of TDG transport. Currently, ad hoc type methods such as simplistic functions or even constant values for TDG are used to specify future values of forebay TDG. Whereas these methods provide an estimate for future reservoir forebay TDG levels, they can be inaccurate and as a result, can provide system-wide TDG inaccuracies, especially during periods of no-spill when tailrace values are direct functions of forebay values.

Currently, there is a need for developing a methodology to predict reservoir forebay TDG levels as a function of the upstream site's tailrace TDG values in conjunction with flows, hydro operations, and reservoir characteristics. Figure 20 illustrates this concept whereby the upstream site's tailrace TDG level is used as an input to the "predictive methodology" to estimate forebay levels at the downstream site. The forebay TDG level then serves as an input to the existing methodology used to predict tailrace TDG levels. 


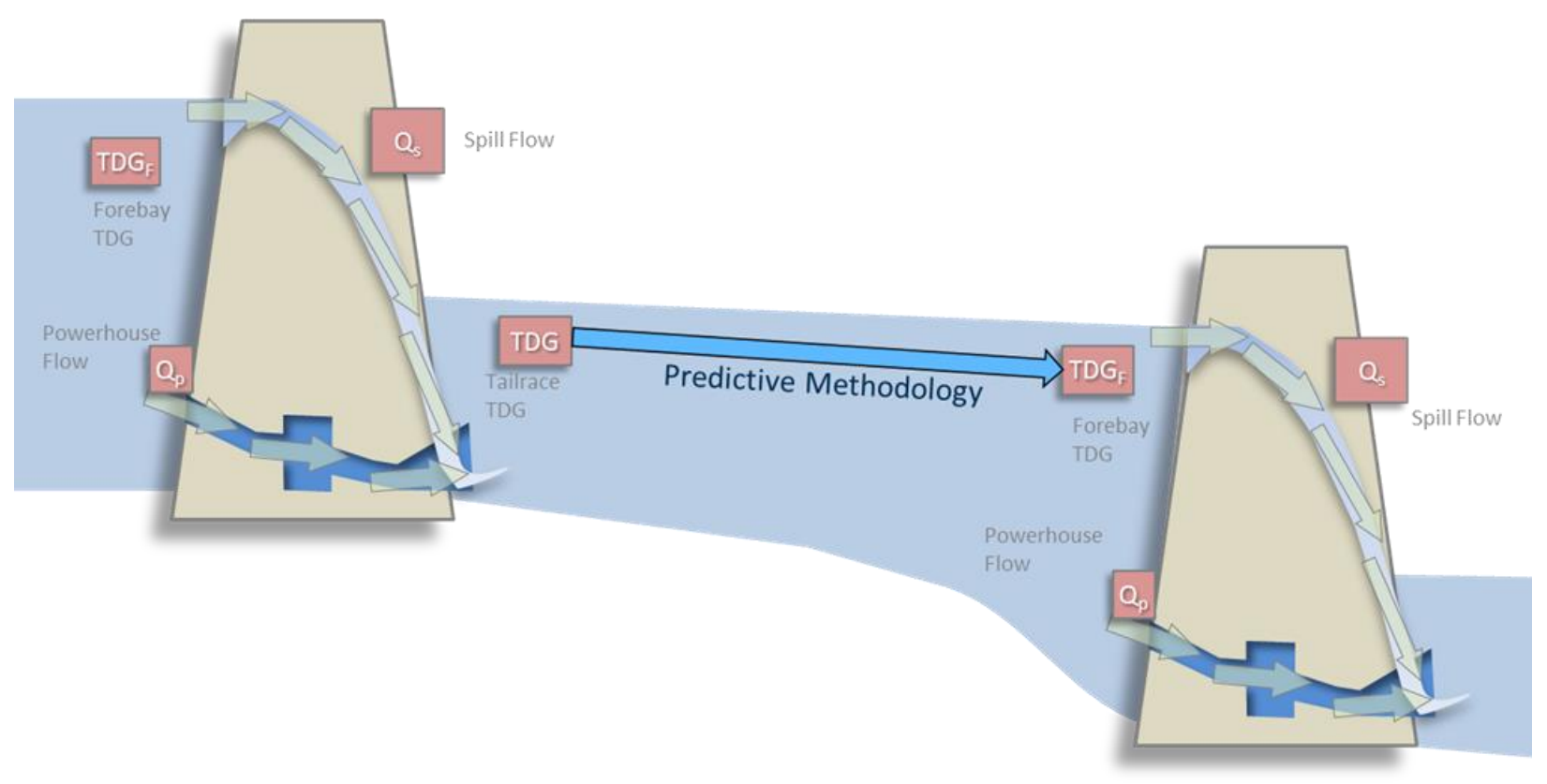

Figure 20 - Schematic depicting reservoir TDG level predictive methodology.

\section{CONCLUSION}

The model for predicting TDG levels in the tailrace of seven mid-Columbia River dams is presented. Performance statistics indicate the model predicts TDG levels with acceptable accuracy across most flow cases for all seven sites investigated. The model provides a better than $92 \%$ coefficient of determination for predicting tailrace TDG levels at Grand Coulee, Chief Joseph, Wells, Rocky Reach, Rock Island, Wanapum, and Priest Rapids. For instances where the model underpredicts TDG levels at high spill flows of greater than roughly 100,000 cfs for Rocky Reach and Wanapum, the predicted TDG levels differ from measured by less than $4 \%$. This is well within the range of acceptability given this model's use in a forecasting application which is accompanied by degrees of uncertainty in predicting hydro flows.

The predictive equations, coefficients, and constraints are incorporated into the water planning and management software, RiverWare. The demands imposed on the hydro system for the mid-Columbia River basin are optimized to yield efficient operational strategies within the context of minimizing the TDG levels at each project. Testing and case comparisons made with RiverWare will serve as a basis from which improved operational decisions can be made. The successful implementation of a TDG minimization methodology used in conjunction with meeting the demands of any hydro system is considered to be an appreciable advancement and step towards environmentally coupled hydro system modeling and planning tools. 


\section{REFERENCES}

Abdul-Aziz, O. I., Wilson, B. N., and Gulliver, J. S. (2007a). Calibration and Validation of an Empirical Dissolved Oxygen Model. Journal of Environmental Engineering, 133(7):698-710.

Abdul-Aziz, O. I., Wilson, B. N., and Gulliver, J. S. (2007b). An Extended Stochastic Harmonic Analysis Algorithm: Application for Dissolved Oxygen. Journal of Water Resources Research, 43(8).

Bouck G.R. (1980). Etiology of gas bubble disease. Transactions of the American Fisheries Society 11, 505-516.

Columbia Basin Research (2000). Columbia River Salmon Passage Model CRiSP 1.6, Theory and Calibration. Columbia Basin Research, School of Aquatic \& Fishery Sciences, University of Washington, December 2000.

Ebel W.J. (1969). Supersaturation of nitrogen in the Columbia River and its effect on salmon and steelhead trout. United States National Marine Fisheries Service Fishery Bulletin 68:1-11.

Geldert, D. A., Gulliver, J. S., and Wilhelms, S. C. (1998). Modeling Dissolved Gas Supersaturation Below Spillway Plunge Pools. Journal of Hydraulic Engineering, 124(5):513-521.

Hadjerioua B., Politano M., DeNeale S., Bender M. and Castro A. (2014). Predicting Total Dissolved Gas (TDG) for the Mid-Columbia River System. Hydrovision International, Nashville, TN.

Hibbs, D. E., and Gulliver, J. S. (1997). Prediction of Effective Saturation Concentration at Spillway Plunge Pools. Journal of Hydraulic Engineering, 123(11):940-949.

Pasha M.F.K., Hadjerioua B., Stewart K., Bender M.D. and Schneider M. (2012). Prediction of total dissolved gas (TDG) at hydropower dams throughout the Columbia River Basin (CRB) - Challenges and proposed Methodology. Hydrovision International, Louisville, KY.

Politano, M. S., Carrica, P. M., Cagri, T., and Weber, L. (2007). A Multidimensional Two-Phase Flow Model for the Total Dissolved Gas Downstream of Spillways. Journal of Hydraulic Research, 45(2):165-177.

Politano, M., Carrica, P., and Weber, L. (2005). Prediction of Total Dissolved Gas Downstream of Spillways Using Multidimensional Two-Phase Flow Model. MECOM 2005 - VIII Congreso Argentino de Mecánica Computational, Buenos Aires, Argentina, November 2005.

Politano, M. S., Carrica, P. M., and Balino, J. L. (2003). About Bubble Breakup Models to Predict Bubble Size Distributions in Homogenous Flows. Journal of Chemical Engineering Communications, 190(3):299-321.

Ran, L., Jia, L., KeFeng, L., Yun, D., and JingJie, F. (2009). Prediction for Supersaturated Total Dissolved Gas in High-Dam Hydropower Projects. Science in China Series E: Technological Sciences. 52(12):3661-3667.

Roesner, L. A., and Norton, W. R. (1971). A Nitrogen Gas Model for the Lower Columbia River. Rep. No. 1-350, Water Resources Engineers, Inc., Walnut Creek, Calif.

Stroud, R.K., Bouck, G.R., and Nebeker, A.V. (1975). Pathology of acute and chronic exposure of salmonid fishes to supersaturated water. Pages 435-449 in W.A. Adams, editor. Chemistry and physics of aqueous gas solutions. The Electro-chemical Society, Princeton, New Jersey, USA. 
Turan, C., Politano, M. S., Carrica, P. M., and Weber, L. (2007). Water entrainment Due to Spillway Surface Jets. International Journal of Computational Fluid Dynamics, 21(3-4):137-153.

Urban, A. L., Gulliver, J. S. and Johnson, D. W. (2008). Modeling Total Dissolved Gas Concentration Downstream of Spillways. Journal of Hydraulic Engineering, 134(5):550-561.

U.S. Army Corps of Engineers (2015 online). Retrieved at www.nwd.usace.army.mil.

USACE. (1997). Dissolved Gas Abatement Study, Phase II. Draft Report, U.S. Army Corps of Engineers Districts, Portland and Walla Walla, North Pacific Region, Portland OR.

USEPA (United States Environmental Protection Agency) (1971). Nitrogen supersaturation in the Columbia and Snake rivers. Summary Report. Region 10, Seattle, Washington, USA.

Weber, L., Huang, H., Lai, Y. and McCoy, A. (2004). Modeling Total Dissolved Gas Production and Transport Downstream of Spillways: Three-Dimensional Development and Applications. International Journal of River Basin Management, 2(3):157-167.

Weitkamp D.E. and Katz M. 1980. A review of dissolved gas supersaturation literature. Transactions of the American Fisheries Society 109, 659-702.

Weitkamp D.E. (2008a). Total dissolved gas supersaturation literature 1980-2007. www.ecy.wa.gov/programs/wq/tmdl/.../TDGeffectsLitRev080615.pdf.

Weitkamp D.E. (2008b). Total dissolved gas supersaturation biological effects, review of literature 19802007. www.ecy.wa.gov/programs/wq/tmdl/.../WeitkampTDGlitRev.pdf .

Witt, A., Gulliver, J., \& Shen, L. (2015). Simulating air entrainment and vortex dynamics in a hydraulic jump. International Journal of Multiphase Flow, 72, 165-180.

Xiao-li, F. Dan, L. and Xiao-feng, Z. (2010). Simulations of the Three-Dimensional Total Dissolved Gas Saturation Downstream of Spillways Under Unsteady Conditions. Journal of Hydrodynamics, 22(4):598-604. 